\title{
Integrated analyses of miRNAome and transcriptome reveal zinc deficiency responses in rice seedlings
}

\author{
Houqing Zeng ${ }^{1 * \dagger} \mathbb{D}$, Xin Zhang ${ }^{2+}$, Ming Ding ${ }^{3}$ and Yiyong Zhu ${ }^{3}$
}

\begin{abstract}
Background: Zinc (Zn) deficiency is one of the most widespread soil constraints affecting rice productivity, but the molecular mechanisms underlying the regulation of Zn deficiency response is still limited. Here, we aim to understand the molecular mechanisms of $Z n$ deficiency response by integrating the analyses of the global miRNA and mRNA expression profiles under Zn deficiency and resupply in rice seedlings by integrating Illumina's high-throughput small RNA sequencing and transcriptome sequencing.

Results: The transcriptome sequencing identified 360 genes that were differentially expressed in the shoots and roots of $\mathrm{Zn}$-deficient rice seedlings, and 97 of them were recovered after $\mathrm{Zn}$ resupply. A total of 68 miRNAs were identified to be differentially expressed under Zn deficiency and/or Zn resupply. The integrated analyses of miRNAome and transcriptome data showed that 12 differentially expressed genes are the potential target genes of $10 \mathrm{Zn}$-responsive miRNAs such as miR171g-5p, miR397b-5p, miR398a-5p and miR528-5p. Some miRNA genes and differentially expressed genes were selected for validation by quantitative RT-PCR, and their expressions were similar to that of the sequencing results.
\end{abstract}

Conclusion: These results provide insights into miRNA-mediated regulatory pathways in Zn deficiency response, and provide candidate genes for genetic improvement of Zn deficiency tolerance in rice.

Keywords: Rice (Oryza sativa), Zinc deficiency, microRNA, Transcriptome, Copper, Oxidative stress

\section{Background}

Zinc is one of the essential micronutrients which acts as a catalytic, regulatory or structural co-factor for a lot of enzymes and regulatory proteins in plants and animals [1]. The well-known Zn-containing proteins in plants include the enzymes like carbonic anhydrase, alcohol dehydrogenase and copper $(\mathrm{Cu}) / \mathrm{Zn}$ superoxide dismutase (CSD), and lots of $\mathrm{Zn}$ finger domain-containing proteins, which function in transcriptional regulation $[1,2]$. Zn deficiency $(-\mathrm{Zn})$ is a serious agricultural problem in arable soils worldwide due to the low availability of $\mathrm{Zn}$ that is caused by factors such as high $\mathrm{pH}$, prolonged flooding, low redox potential, and high contents of bicarbonate, organic matter and phosphorus [3]. Zn deficiency in soils and plants can also result in human

\footnotetext{
* Correspondence: zenghq@hznu.edu.cn

† Houqing Zeng and Xin Zhang contributed equally to this work.

${ }^{1}$ College of Life and Environmental Sciences, Hangzhou Normal University, Hangzhou 311121, China

Full list of author information is available at the end of the article
}

malnutrition through the intake of food that contains low concentrations of $\mathrm{Zn}$ and other micronutrients [4]. It is estimated that one-third of the human population, especially children and women suffer from $\mathrm{Zn}$-deficiency-related health problems [5]. Thus, studies to better understand the mechanisms of $\mathrm{Zn}$ deficiency response and tolerance in plants can help to develop crops with increased $\mathrm{Zn}$ use efficiency, $\mathrm{Zn}$ concentration, and $\mathrm{Zn}$ deficiency tolerance $[4,6-8]$.

Rice (Oryza sativa) is the second most cultivated crop and the main staple food for three billion people in the world. However, $\mathrm{Zn}$ deficiency is becoming one of the most widespread soil constraints affecting rice productivity $[9,10]$. Much effects have been made to elucidate the physiological and biochemical mechanisms associated with $\mathrm{Zn}$ deficiency response and tolerance in plants [11-13]. These mechanisms include increasing $\mathrm{Zn}$ availability for root uptake by adjusting the root system architecture, releasing of phytosiderophores and organic acids, and formation of arbuscular mycorrhiza symbiosis 
$[6,14,15]$; expanding the generation of crown roots [16]; involvement of transporters such as ZRT, IRTrelated proteins (ZIPs), metal tolerance proteins and heavy metal tolerance family proteins in $\mathrm{Zn}$ uptake and translocation [17-21]; adjusting the expression of $\mathrm{Zn}$ requiring enzymes $[2,13]$. Recently, transcriptomic profilings were analyzed to identify Zn-responsive genes in plants [22-24]. Four genes up-regulated in Zn-efficient rice varieties under $\mathrm{Zn}$ deficiency were reported to be candidate genes conferring Zn efficiency [22]. A large number of $\mathrm{Zn}$ deficiency responsive genes were found to be associated with calcium, sugar and hormonal signals in soybean [23]. Although some progress has been made, the molecular regulatory mechanisms underlying $\mathrm{Zn}$ deficiency response and tolerance is still limited.

microRNAs (miRNAs) are endogenous small noncoding RNAs which are 20 to 24 nucleotides in size and generated from a single-stranded RNA precursor with a hairpin secondary structure [25]. They are known to direct target mRNA cleavage, translational repression, and DNA methylation on the basis of sequence complementarity with their target genes. In plants, miRNAs mainly direct mRNA cleavage and have important functions in the regulation of growth and development and various environmental stress responses [26-32]. For example, miR156 is involved in controlling rice grain size, panicle branching, crown root development and flowering time by targeting SPL transcription factor genes [27, 33, 34]; miR164 regulates lateral root development, leaf senescence, grain yield and drought stress tolerance [35-37]. miRNAs also regulate plant responses to multiple nutrient deprivation stresses and are involved in nutrient homeostasis regulation [38-40]. For instance, miR399, miR827 and miR778 are induced by phosphate deficiency and are involved in regulating phosphate homeostasis by regulating ubiquitin-conjugating E2 enzyme PHO2, RING-type ubiquitin E3 ligase NLA, and histone H3 lysine 9 (H3K9) methyltransferase SUVH6, respectively [40-43]; miR397, miR398, miR408 and miR857 are involved in $\mathrm{Cu}$ homeostasis regulation by controlling the expression of $\mathrm{Cu}$-containing proteins [39, 44]. By using miRNA microarray, eight miRNA families were identified to be responsive to $\mathrm{Zn}$ deficiency in Sorghum bicolor, and two $\mathrm{Cu} / \mathrm{Zn}$ superoxide dismutase genes $S b C S D 1$ and SbCSD2 were found be targeted by miR398 and miR528, respectively [2]. However, to our knowledge, there is still no report on whether and how miRNAs regulate $\mathrm{Zn}$ deficiency responses in rice. In this study, we investigated the molecular mechanisms in response to $\mathrm{Zn}$ deficiency by integrating miRNAome and transcriptome analyses in rice seedlings. A comprehensive and integrated analysis of these different datasets have identified potential miRNA-mRNA interactions under $\mathrm{Zn}$ deficiency in rice.

\section{Results}

Transcriptome profilings in response to $\mathrm{Zn}$ deficiency and $Z n$ resupply by RNA sequencing

After experiencing $\mathrm{Zn}$ deficiency for 14 days, the $\mathrm{Zn}$ concentrations in shoots and roots were significantly decreased, and the $\mathrm{Zn}$ concentrations in shoots and roots of Zn-deficient seedlings were then significantly increased after $\mathrm{Zn}$ resupply for 3 days (Fig. 1a, b-d). No significant difference was observed in shoot and root biomass under Zn deficiency (Fig. 1e). Consistent with the phenotype observed in Sorghum [2], the primary root length were dramatically increased by $\mathrm{Zn}$ deficiency (Fig. 1c, f). These results showed that physiological adaptive responses to $-Z n$ and $Z n$ resupply have been exhibited.

We then analyzed the global transcriptome profiles of rice shoots and roots in responses to $-\mathrm{Zn}$ and $\mathrm{Zn}$ resupply by RNA sequencing. The $\mathrm{Zn}$ resupply treatments were used to investigate the recovery of Zn-responsive genes or miRNAs under Zn stress. By Illumina's deep sequencing, a total of 28.6 to 55.2 million reliable clean reads were obtained from each library after excluding the low-quality reads, and most of the clean reads (86.8-97.3\%) from each library could be mapped to the rice reference genome (https://rapdb.dna.affrc.go.jp/) (Additional file 1: Table S2). The Pearson's correlation ( $\mathrm{R}$ value) of the three biological replicates of each sample was around $90 \%$, indicating the high reliability of the replicates (Additional file 2: Figure S1). The abundance of mapped transcripts was measured in terms of FPKM, and a total of 34,716 gene loci were detected in all these samples (Additional file 1: Table S3).

Differential expression analysis (fold change $\geq 2$ and FDR $\leq$ 0.05 ) showed that a total of 151, 227, 123, and 205 genes were differentially expressed in $\mathrm{Zn}$-deficient shoots (ZMS/ ZPS), Zn-deficient roots (ZMR/ZPR), Zn-resupply shoots (ZRS/ZMS) and Zn-resupply roots (ZRR/ZMR), respectively (Fig. 2a; Additional file 1: Tables S4-S7). Venn diagram analysis showed that a total of $97 \mathrm{Zn}$-deficiency-responsive genes were recovered by $\mathrm{Zn}$ resupply in shoots and/or roots (Fig. $2 \mathrm{~b}$ and c), suggesting a causal relationship between the expression levels of these genes and the levels of $\mathrm{Zn}$ in the growth media. Among the 89 up-regulated and 62 down-regulated genes in shoots (ZMS/ZPS up and down), 32 (36.0\%) and 14 (22.6\%) genes were recovered after $\mathrm{Zn}$ resupply treatment (ZRS/ZMS down and up), respectively (Table 1). Among the 117 up-regulated and 110 down-regulated genes in roots (ZMR/ZPR up and down), 40 (34.2\%) and 18 (16.4\%) genes were recovered after $\mathrm{Zn}$ resupply treatment (ZRR/ZMR down and up), respectively (Table 2). Seven genes (Os10g0328600, Os04g0280500, Os04g0561500, Os06g0566 201, Os06g0566300, Os08g0207500, and Os07g0232800) were commonly recovered by $\mathrm{Zn}$ resupply in both roots and shoots; three of them encode $\mathrm{Zn}$ transporters (OsZIP4, OsZIP8 and OsZIP10). GO enrichment analysis (FDR $<0.05)$ 

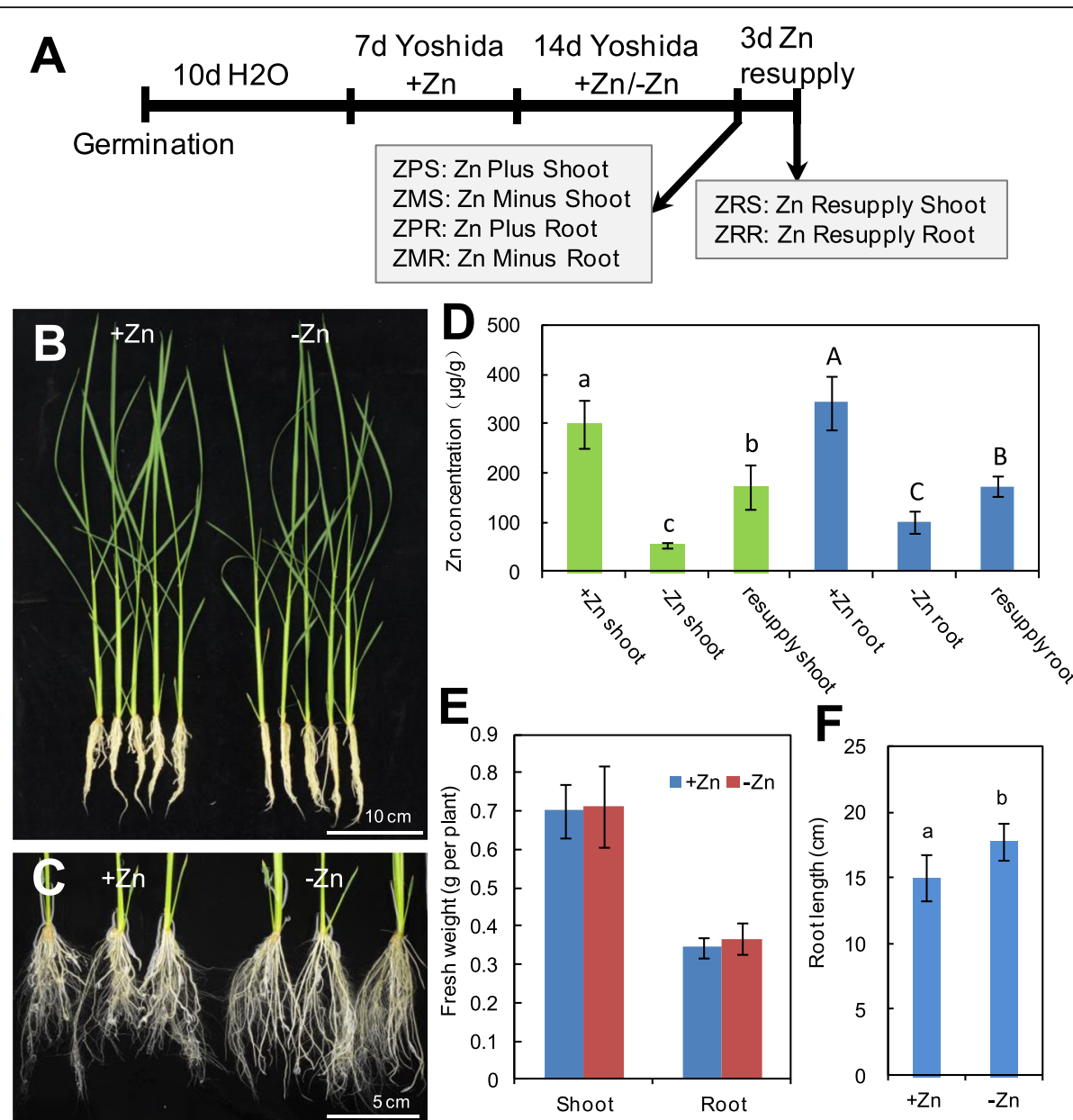

Fig. 1 Physiological responses of rice seedlings to Zn deficiency and Zn resupply. a Schematic representation of the experimental design showing the duration of seedling growth and treatments of $Z n$ deficiency and Zn resupply. Morphological appearance of the whole seedlings (b) and the roots (c) after Zn deficiency treatment for 14 days. $\mathbf{d}$ Zn concentration in the shoots and roots of rice seedlings after Zn deficiency for 14 days and Zn resupply for 3 days. Fresh weight of shoots and roots (e) and root length (f) of rice seedlings after Zn deficiency treatment for 14 days. Data are means \pm SD from 3 samples for $(\mathbf{d})$, and 10 samples for (e and $\mathbf{f}$ ). Different letters indicate that the values are significantly different at $P<0.05$ (Student's t-test)

revealed that zinc ion transmembrane transport (GO: 0071577) and zinc ion transmembrane transporter activity (GO:0005385) were significantly enriched in Zn-deficiency up-regulated DEGs and Zn-resupply down-regulated DEGs in both shoots and roots, while threonine synthase activity (GO:0004795) and L-methionine biosynthetic process from methylthioadenosine (GO:0019509) were significantly enriched in Zn-deficiency down-regulated DEGs in shoots and roots, respectively (Additional file 1: Table S8).

\section{miRNA profilings in rice responses to $Z n$ deficiency and $Z n$ resupply}

Sequencing results showed that 8.8 to 15.3 million raw reads were obtained for each of the 18 libraries, and after discarding low-quality, junk and adaptor reads, repeats, and Rfam RNA and mRNA sequences, 38.3 to $56.0 \%$ of the total reads were valid reads in these libraries (Additional file 1: Table
S9). The size distribution analysis showed that small RNAs from the six samples were primarily enriched in sequences with 21- to 24-nt, and 24-nt was the most dominant segment (Additional file 1: Table S10; Additional file 2: Figure S2), which is in concurrence with previous studies [45]. Pearson correlation analysis of three biological replicates of each sample revealed high correlation coefficients ranging from 0.80 to 0.99 (Additional file 2: Figure S3), indicating the high reliability of the replicates. The clean reads were searched against the miRNAs of rice and other plant species from miRBase, and a total of $498 \mathrm{known} /$ conserved miRNAs were identified from all samples. The reads which could not be mapped to miRBase were subjected to novel miRNA prediction. After the removal of small RNAs which do not meet the plant miRNA criteria (eg. length $<20$ or $>24$, no hairpin structure, less than 10 reads in a sample), a final set of 370 novel miRNA genes was obtained (Additional file 1: Table S11). 


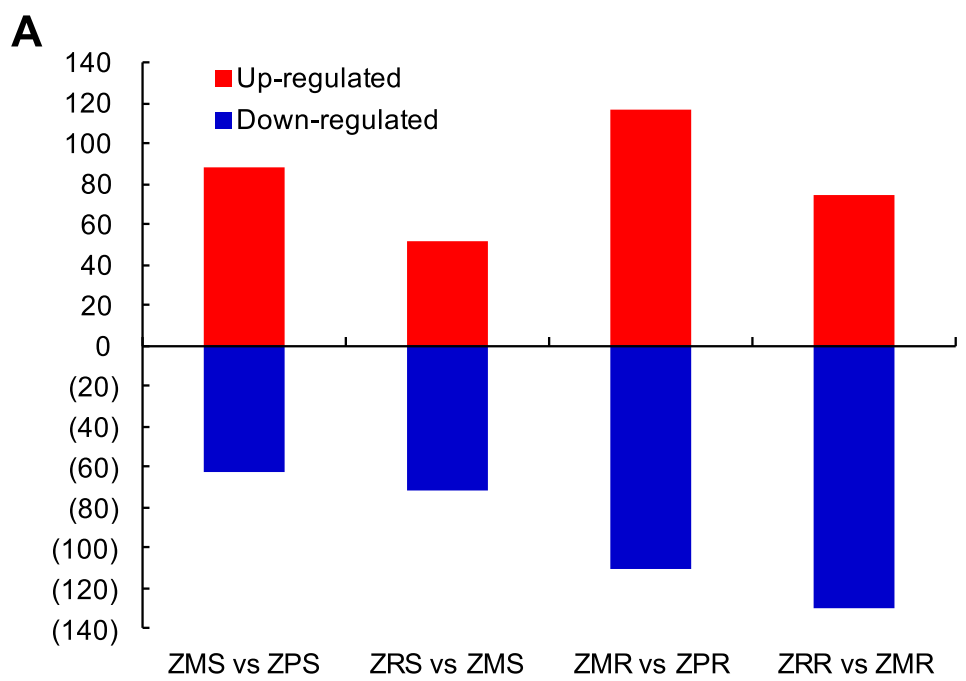

B
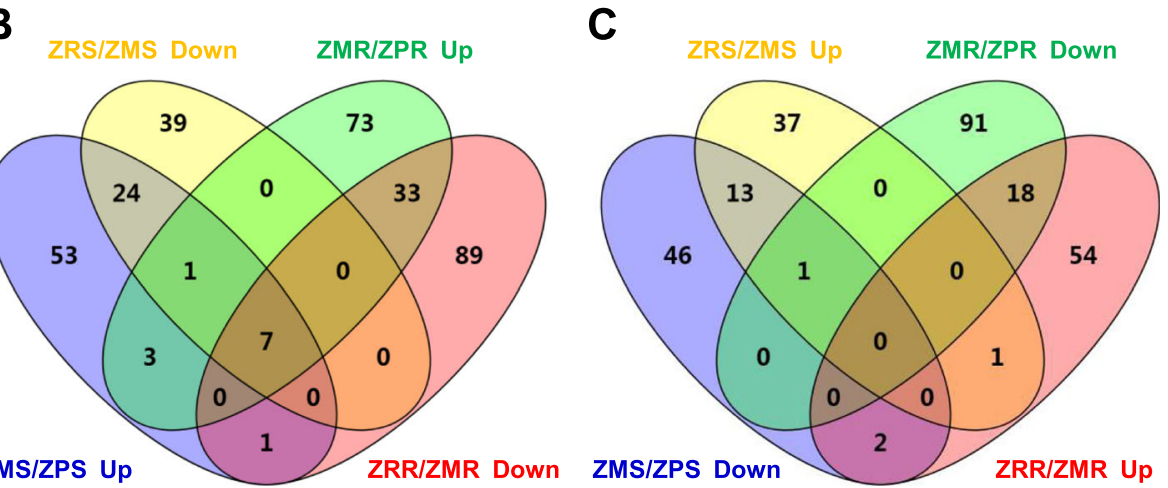

Fig. 2 Overview of the differentially expressed genes (DEGs) in responses to $14 \mathrm{~d}$ of $\mathrm{Zn}$ deprivation and/or $3 \mathrm{~d}$ of $\mathrm{Zn}$ resupply. a The number of DEGs in responses to $Z n$ deprivation and/or $Z n$ resupply in rice roots and leaves $(P<0.05, F D R<0.05)$. $\mathbf{b}$ Venn diagram representing the overlap of the $Z n$ deficiency up-regulated DEGs and $Z n$ resupply down-regulated DEGs in roots and leaves. $\mathbf{c}$ Venn diagram representing the overlap of the Zn deficiency down-regulated DEGs and Zn resupply up-regulated DEGs in roots and leaves

A total of 68 miRNAs (including 38 novel miRNAs) were found to be differentially expressed under Zn deficiency (ZMS/ZPS in shoots and ZMR/ZPR in roots) and/or Zn resupply (ZRS/ZMS in shoots and ZRR/ZMR in roots); 38 miRNAs were differentially expressed under $\mathrm{Zn}$ deficiency and 44 miRNAs were differentially expressed under $\mathrm{Zn}$ resupply; 14 miRNAs were commonly responsive to $\mathrm{Zn}$ deficiency and $\mathrm{Zn}$ resupply (Additional file 1: Table S12; Fig. 3; Additional file 2: Figures S4 and S5). Of these Zn-responsive miRNAs, 12 and 11 were up-regulated by $Z n$ deficiency in shoots and roots, respectively; 2 and 12 were down-regulated by $\mathrm{Zn}$ deficiency in shoots and roots, respectively (Additional file 2: Figure S4). However, none of these miRNAs were commonly responsive to $\mathrm{Zn}$ deficiency in both shoots and roots, suggesting the distinct miRNAmediated regulatory networks in shoots and roots under Zn deficiency. Seventeen and 27 miRNAs were found to be responsive to $\mathrm{Zn}$ resupply in shoots and roots, respectively. Interestingly, four and seven Zn-deficiency- responsive miRNAs could be recovered by $\mathrm{Zn}$ resupply in shoots and roots, respectively (Additional file 2: Figure S4). For example, osa-miR398a-5p, nov-miR7, nov-miR21, and nov-miR38 were induced by Zn deficiency but were repressed by $\mathrm{Zn}$ resupply in shoots; osamiR818a-3p, osa-miR1428a-3p, and osa-miR5532-5p were induced by $\mathrm{Zn}$ deficiency but were repressed by $\mathrm{Zn}$ resupply in roots (Fig. 3). Two miRNAs showed similar expression pattern under $\mathrm{Zn}$ deficiency and $\mathrm{Zn}$ resupply; miR397b-5p was induced by both $\mathrm{Zn}$ deficiency and $\mathrm{Zn}$ resupply in roots, and nov-miR27 was repressed by $\mathrm{Zn}$ deficiency and $\mathrm{Zn}$ resupply in roots and shoots, respectively (Fig. 3), suggesting the complex regulations of these miRNAs under Zn deficiency and resupply.

\section{Identification of potential target genes of $\mathrm{Zn}$-responsive miRNAs}

To understand the potential biological function of these Zn-deficiency- and/or Zn-resupply-responsive miRNAs, miRNA-targeted genes were predicted using an online 
Table 1 Zn deficiency-induced or repressed genes returning to basal level after Zn resupply in the shoots. The FPKM value represents mean \pm SD (standard deviation) of three biological replicates. Note: MSTRG.18312, MSTRG.5686, and MSTRG.5688 are three new loci. "-" means no description

\begin{tabular}{|c|c|c|c|c|}
\hline Gene & Description & ZPS (FPKM) & ZMS (FPKM) & ZRS (FPKM) \\
\hline Os02g0192700 & Similar to Thioredoxin peroxidase & 0 & $68.55 \pm 60.14$ & 0 \\
\hline Os02g0663100 & GRAS transcription factor domain containing protein & 0 & $22.24 \pm 4.50$ & 0 \\
\hline Os05g0102000 & SAM dependent carboxyl methyltransferase family protein & 0 & $19.82 \pm 17.40$ & 0 \\
\hline Os10g0493300 & Hypothetical conserved gene & 0 & $13.02 \pm 13.99$ & 0 \\
\hline Os04g0382900 & Conserved hypothetical protein & 0 & $6.38 \pm 9.55$ & 0 \\
\hline Os01g0504100 & Protein of unknown function DUF250 domain containing protein & 0 & $6.10 \pm 5.29$ & 0 \\
\hline Os10g0528400 & Glutathione S-transferase, C-terminal-like domain containing protein & 0 & $5.39 \pm 4.72$ & 0 \\
\hline Os12g0103500 & Ribosome-inactivating protein domain containing protein & 0 & $4.59 \pm 4.11$ & 0 \\
\hline Os09g0116600 & Hypothetical gene & 0 & $4.06 \pm 5.68$ & 0 \\
\hline Os11g0490300 & Hypothetical conserved gene & 0 & $3.26 \pm 2.85$ & 0 \\
\hline Os03g0746700 & Conserved hypothetical protein & 0 & $3.08 \pm 2.72$ & 0 \\
\hline Os01g0532300 & Conserved hypothetical protein & 0 & $2.28 \pm 2.08$ & 0 \\
\hline Os06g0208951 & Conserved hypothetical protein & 0 & $2.00 \pm 1.81$ & 0 \\
\hline Os05g0562800 & Similar to predicted protein & 0 & $1.90 \pm 2.55$ & 0 \\
\hline Os03g0272900 & DVL family protein & 0 & $1.69 \pm 1.59$ & 0 \\
\hline Os09g0444800 & Protein of unknown function DUF716 family protein & 0 & $1.57 \pm 1.36$ & 0 \\
\hline Os10g0328600 & - & 0 & $1.39 \pm 0.88$ & 0 \\
\hline Os02g0550400 & Tetratricopeptide-like helical domain containing protein & 0 & $1.10 \pm 0.95$ & 0 \\
\hline Os07g0586900 & GRAS transcription factor domain containing protein & 0 & $1.02 \pm 1.00$ & 0 \\
\hline Os09g0412900 & Pentatricopeptide repeat domain containing protein & 0 & $0.64 \pm 0.64$ & 0 \\
\hline Os11g0606200 & Similar to Leucine Rich Repeat family protein & 0 & $0.49 \pm 0.49$ & 0 \\
\hline Os10g0328600 & Hypothetical protein & $0.02 \pm 0.01$ & $8.27 \pm 1.81$ & $0.18 \pm 0.09$ \\
\hline Os04g0280500 & Similar to Non-S-locus F-box-like protein 2011 & $0.03 \pm 0.03$ & $10.03 \pm 1.61$ & $0.49 \pm 0.22$ \\
\hline Os04g0561500 & Similar to Prolyl endopeptidase (Post-proline cleaving enzyme) & $1.78 \pm 0.63$ & $204.72 \pm 11.10$ & $18.07 \pm 8.12$ \\
\hline Os06g0566201 & - & $1.38 \pm 0.28$ & $20.93 \pm 10.37$ & $1.48 \pm 0.19$ \\
\hline Os02g0306401 & Similar to Nicotianamine aminotransferase A & $5.81 \pm 1.28$ & $76.61 \pm 8.44$ & $15.04 \pm 5.84$ \\
\hline Os06g0566300 & Zinc transporter OsZIP10 & $2.97 \pm 0.26$ & $38.94 \pm 10.62$ & $1.84 \pm 0.34$ \\
\hline MSTRG.18312 & - & $0.18 \pm 0.02$ & $1.92 \pm 0.42$ & $0.17 \pm 0.08$ \\
\hline Os08g0207500 & Zinc transporter OsZIP4 & $1.7 \pm 0.42$ & $16.32 \pm 8.27$ & $1.9 \pm 0.39$ \\
\hline Os07g0232800 & Zinc transporter OsZIP8 & $6.84 \pm 1.31$ & $50.73 \pm 5.05$ & $11.81 \pm 6.25$ \\
\hline Os03g0293100 & Conserved hypothetical protein & $7.25 \pm 0.67$ & $44.01 \pm 14.47$ & $7.78 \pm 2.48$ \\
\hline Os09g0485900 & Similar to 605 ribosomal protein L9 (Gibberellin-regulated protein) & $35.05 \pm 6.96$ & $164.62 \pm 105.32$ & $29.16 \pm 13.21$ \\
\hline Os11g0577866 & Conserved hypothetical protein & $9.27 \pm 2.32$ & 0 & $7.93 \pm 4.44$ \\
\hline Os06g0715200 & Conserved hypothetical protein & $8.48 \pm 7.9$ & 0 & $15.11 \pm 6.49$ \\
\hline Os08g0526100 & NAD(P)-binding domain containing protein & $6.15 \pm 5.96$ & 0 & $4.27 \pm 3.76$ \\
\hline Os01g0243450 & Non-protein coding transcript & $3.96 \pm 0.68$ & 0 & $1.66 \pm 1.54$ \\
\hline Os05g0528701 & Non-protein coding transcript & $1.81 \pm 1.59$ & 0 & $1.36 \pm 1.27$ \\
\hline Os01g0856800 & Pleckstrin homology-type domain containing protein & $0.86 \pm 0.8$ & 0 & $1.14 \pm 0.98$ \\
\hline Os09g0460300 & Alpha/beta hydrolase fold-3 domain containing protein & $0.8 \pm 0.74$ & 0 & $9.12 \pm 8.68$ \\
\hline Os08g0451201 & - & $0.69 \pm 0.67$ & 0 & $0.85 \pm 0.76$ \\
\hline Os03g0411900 & - & $0.64 \pm 0.73$ & 0 & $0.35 \pm 0.32$ \\
\hline Os01g0880250 & Hypothetical protein & $6.77 \pm 6.57$ & $0.03 \pm 0.02$ & $3.64 \pm 5.01$ \\
\hline
\end{tabular}


Table 1 Zn deficiency-induced or repressed genes returning to basal level after Zn resupply in the shoots. The FPKM value represents mean \pm SD (standard deviation) of three biological replicates. Note: MSTRG.18312, MSTRG.5686, and MSTRG.5688 are three new loci. "-" means no description (Continued)

\begin{tabular}{lllll}
\hline Gene & Description & ZPS (FPKM) & ZMS (FPKM) & ZRS (FPKM) \\
\hline MSTRG.5686 & - & $78.84 \pm 109.73$ & $0.42 \pm 0.31$ & $227.64 \pm 346.33$ \\
Os06g0639800 & Cytochrome P450 family protein & $5.69 \pm 0.85$ & $0.06 \pm 0.10$ & $5.2 \pm 2.26$ \\
MSTRG.5688 & - & $7.28 \pm 9.58$ & $0.20 \pm 0.06$ & $23.02 \pm 34.31$ \\
Os03g0592500 & - & $66.95 \pm 83.98$ & $5.22 \pm 1.37$ & $30.1 \pm 25.42$ \\
\hline
\end{tabular}

tool psRNATarget [46]. A total of 799 potential target genes were identified for these $68 \mathrm{Zn}$-responsive miRNAs (Additional file 1: Table S13). At least 19 target genes of the four Zn-responsive miRNAs (miR398, miR408, miR528, miR397) have been previously validated through experiments like RNA ligase-mediated 5' rapid amplification of cDNA ends (RLM 5'-RACE), degradome sequencing, and genetic analysis (Table 3 ) [47-49]; most of them were $\mathrm{Cu}$-containing proteins and were involved in $\mathrm{Cu}$ homeostasis, reactive oxygen species (ROS) homeostasis, photosynthesis and stress tolerance [49-58].

To further elucidate the potential biological functions of the predicted target genes in $\mathrm{Zn}$ deficiency response, GO enrichment analysis was performed. In total, $26 \mathrm{GO}$ terms of biological process group, $19 \mathrm{GO}$ terms of molecular function group, and $18 \mathrm{GO}$ terms of cellular component group were significantly enriched $(\mathrm{FDR}<0.05)$ ( Fig. 4; Additional file 2: Figure S6 and S7). Among the enriched molecular functions, the most significant GO terms were oxidoreductase activity (GO:0016682), laccase activity (GO:0008471), serine-type peptidase activity (GO:0008236), $\mathrm{Cu}$ ion binding (GO: 0005507), and serine hydrolase activity (GO:0017171) (Fig. 4). Among the enriched biological processes, the most enriched GO terms were lignin metabolic process (GO:0009808), phenylpropanoid catabolic process (GO:0009808), cellular amino acid derivative catabolic process (GO:0042219), secondary metabolic process (GO:0019748), and proteolysis (GO: 0006508) (Additional file 2: Figure S6). In cellular component group, apoplast (GO:0048046), chromatin (GO:0000785), and photosynthetic membrane (GO:0034357) were the most over-represented terms (Additional file 2: Figure S7).

\section{Integrated analysis of miRNAome and transcriptome}

Given that miRNAs negatively regulate the expression of their target mRNAs by target cleavage, the expression patterns of miRNAs generally show an inverse correlation with those of their target genes. By integrating transcriptome and miRNAome data, twelve DEGs under - $\mathrm{Zn}$ and/ or $\mathrm{Zn}$ resupply were predicted to be targeted by $10 \mathrm{miR}$ NAs (including four known and six novel miRNAs) that were responsive to $-\mathrm{Zn}$ and/or $\mathrm{Zn}$ resupply (Table 4). Half of the potential target DEGs showed a different response to $\mathrm{Zn}$ deficiency or $\mathrm{Zn}$ resupply as compared with the corresponding miRNAs, suggesting the negative regulation of these miRNAs on their potential target genes. For example, miR397b-5p was up-regulated by $\mathrm{Zn}$ resupply, while its potential target genes OsLAC11 (Os03g0273200) and OsLAC29 (Os12g0258700) were up-regulated by - Zn or down-regulated by $\mathrm{Zn}$ resupply; osa-miR398a-5p was up-regulated by $\mathrm{Zn}$ deficiency, while its potential target gene Os07g0213800 was down-regulated; nov-miR4 was down-regulated by $\mathrm{Zn}$ resupply, while its potential target gene Os01g0358700 was up-regulated; nov-miR6 was down-regulated by $\mathrm{Zn}$ deficiency, while it potential target gene Os04g0623901 was up-regulated; nov-miR23 was down-regulated by Zn deficiency, while its potential target gene Os01g0923900 was down-regulated by Zn-resupply. However, half of the potential target genes showed similar expression patterns with the miRNAs (Table 4). This may be caused by the following reasons: these genes are inauthentic targets of the miRNAs; there are complicated regulation of the potential target genes; the potential target genes are regulated by translational repression but not by transcript cleavage.

\section{Confirmation of miRNAome and transcriptome results by qRT-PCR}

To confirm the small RNA sequencing results, seven $\mathrm{Zn}$ responsive miRNAs were randomly selected for expression validation by qRT-PCR. Primary miRNAs (pri-miRNAs), which contain a characteristic hairpin structure, are transcribed from MIR genes through polymerase II in plants and can be used to indicate the expression level of mature miRNAs [59]. Here, the primary transcripts of these miRNAs were analyzed using gene-specific primers based on the sequences of the corresponding miRNA genes. The expression of pri-miRNAs were almost consistent with the small RNA sequencing results of mature miRNAs. For example, primiR398a was up-regulated by $\mathrm{Zn}$ deficiency and downregulated by $\mathrm{Zn}$ resupply; pri-miR408 was up-regulated by Zn resupply; pri-miR528 was up-regulated by Zn deficiency (Fig. 5). However, pri-miR397b and pri-nov-miR28 were repressed by $\mathrm{Zn}$ deficiency, which is inconsistent with the expression of mature miR397b and nov-miR28, suggesting the different responses of these pri-miRNAs and mature miRNAs under Zn deficiency. To confirm the RNA sequencing results, four $\mathrm{Zn}$-responsive genes (Os05g0472400, 
Table 2 Zn deficiency-induced or repressed genes returning to basal level after Zn resupply in the roots. The FPKM value represents mean \pm SD of three biological replicates. Note: MSTRG.6046, MSTRG.22477, and MSTRG.30070 are three new loci. "-" means no description

\begin{tabular}{|c|c|c|c|c|}
\hline Gene & Description & ZPR (FPKM) & ZMR (FPKM) & ZRR (FPKM) \\
\hline Os08g0235800 & Similar to WRKY transcription factor 25 & 0 & $23.49 \pm 22.4$ & 0 \\
\hline Os01g0896400 & Similar to JHL23J11.5 protein & 0 & $11.66 \pm 18.26$ & 0 \\
\hline Os01g0693800 & Similar to Threonine synthase, chloroplast precursor & 0 & $11.17 \pm 9.72$ & 0 \\
\hline Os05g0121500 & Similar to structural constituent of ribosome & 0 & $6.57 \pm 6.92$ & 0 \\
\hline Os03g0191900 & Pathogenesis-related transcriptional factor and ERF domain containing protein & 0 & $5.76 \pm 5.66$ & 0 \\
\hline Os11g0107600 & Similar to prenylated Rab receptor 2 & 0 & $5.35 \pm 4.77$ & 0 \\
\hline Os02g0455400 & Hypothetical conserved gene & 0 & $4.66 \pm 4.04$ & 0 \\
\hline Os03g0852400 & Conserved hypothetical protein & 0 & $4.28 \pm 3.71$ & 0 \\
\hline Os03g0280750 & Plant disease resistance response protein family protein & 0 & $3.48 \pm 3.11$ & 0 \\
\hline Os05g0571600 & Conserved hypothetical protein & 0 & $3.2 \pm 2.77$ & 0 \\
\hline Os02g0310400 & Conserved hypothetical protein & 0 & $3.08 \pm 2.68$ & 0 \\
\hline Os05g0525900 & Similar to Zing finger transcription factor PEl1 & 0 & $2.67 \pm 2.32$ & 0 \\
\hline Os01g0742300 & 3-hydroxyacid dehydrogenase/reductase domain containing protein & 0 & $1.96 \pm 1.79$ & 0 \\
\hline Os03g0253200 & Similar to WAG1; kinase & 0 & $1.91 \pm 1.66$ & 0 \\
\hline Os06g0192800 & Similar to RING-H2 finger protein ATL1R (RING-H2 finger protein ATL8) & 0 & $1.59 \pm 1.78$ & 0 \\
\hline Os01g0234700 & Harpin-induced 1 domain containing protein & 0 & $1.25 \pm 1.4$ & 0 \\
\hline Os03g0103400 & GRAS transcription factor domain containing protein & 0 & $0.99 \pm 0.89$ & 0 \\
\hline Os10g0490100 & Virulence factor, pectin lyase fold family protein & 0 & $0.98 \pm 0.88$ & 0 \\
\hline Os03g0245700 & Similar to senescence-associated protein 15 & 0 & $0.96 \pm 0.84$ & 0 \\
\hline Os05g0578100 & Protein of unknown function DUF1645 family protein & 0 & $0.82 \pm 0.15$ & 0 \\
\hline Os01g0584300 & - & 0 & $2.42 \pm 2.23$ & 0 \\
\hline Os04g0685700 & Similar to $\mathrm{H} 0723 \mathrm{CO} .4$ protein & 0 & $0.75 \pm 0.65$ & 0 \\
\hline Os07g0585900 & Hypothetical conserved gene & 0 & $0.75 \pm 0.66$ & 0 \\
\hline MSTRG.6046 & - & 0 & $0.66 \pm 0.7$ & 0 \\
\hline Os02g0242900 & Similar to hydroquinone glucosyltransferase & 0 & $0.63 \pm 0.6$ & 0 \\
\hline Os11g0256100 & Pentatricopeptide repeat domain containing protein & 0 & $0.41 \pm 0.35$ & 0 \\
\hline Os12g0137700 & Sulfotransferase family protein & $0.01 \pm 0.01$ & $3.9 \pm 3.66$ & $0.03 \pm 0.04$ \\
\hline Os04g0280500 & Similar to Non-S-locus F-box-like protein 2011 & $0.07 \pm 0.02$ & $18.01 \pm 5.28$ & $0.31 \pm 0.22$ \\
\hline Os10g0553600 & Exostosin-like family protein & $0.01 \pm 0.01$ & $1.69 \pm 0.89$ & $0.01 \pm 0.01$ \\
\hline Os08g0207401 & Hypothetical gene & $0.01 \pm 0.03$ & $0.97 \pm 0.34$ & $0.04 \pm 0.03$ \\
\hline Os10g0328600 & Hypothetical protein & $0.11 \pm 0.09$ & $6.52 \pm 1.13$ & $0.13 \pm 0.03$ \\
\hline Os06g0566201 & - & $0.4 \pm 0.03$ & $13.82 \pm 8.44$ & $0.88 \pm 0.15$ \\
\hline Os06g0566300 & Zinc transporter OsZIP10 & $0.88 \pm 0.12$ & $23.97 \pm 7.22$ & $1.58 \pm 0.07$ \\
\hline Os04g0561500 & Similar to Prolyl endopeptidase (Post-proline cleaving enzyme) & $7.38 \pm 0.4$ & $155.99 \pm 10.59$ & $10.99 \pm 4.64$ \\
\hline Os05g0472400 & Similar to Zinc transporter 9 & $1.48 \pm 0.25$ & $29.79 \pm 5.17$ & $5.12 \pm 2.05$ \\
\hline Os07g0232800 & Zinc transporter OsZIP8 & $0.75 \pm 0.23$ & $14.84 \pm 1.15$ & $0.99 \pm 0.31$ \\
\hline Os04g0304400 & Similar to MADS-box protein AGL16-II & $0.51 \pm 0.04$ & $8.26 \pm 3.48$ & $1.83 \pm 0.09$ \\
\hline Os08g0207500 & Zinc transporter OsZIP4 & $2.9 \pm 0.24$ & $28.12 \pm 9.16$ & $4.29 \pm 1.91$ \\
\hline MSTRG.22477 & - & $0.34 \pm 0.11$ & $3.12 \pm 0.97$ & $0.09 \pm 0.06$ \\
\hline MSTRG.30070 & - & $21.6 \pm 19.8$ & $91.8 \pm 29.43$ & $0.46 \pm 0.24$ \\
\hline Os06g0131300 & Arginine decarboxylase, Chilling stress respons & $98.89 \pm 73.37$ & 0 & $123.68 \pm 112.96$ \\
\hline Os03g0244950 & Heat shock protein DnaJ, N-terminal domain containing protein & $6.6 \pm 7.68$ & 0 & $3.45 \pm 3.04$ \\
\hline Os06g0505501 & Non-protein coding transcript & $3.46 \pm 1.52$ & 0 & $1.61 \pm 1.6$ \\
\hline
\end{tabular}


Table 2 Zn deficiency-induced or repressed genes returning to basal level after Zn resupply in the roots. The FPKM value represents mean \pm SD of three biological replicates. Note: MSTRG.6046, MSTRG.22477, and MSTRG.30070 are three new loci. "-" means no description (Continued)

\begin{tabular}{lllll}
\hline Gene & Description & ZPR (FPKM) & ZMR (FPKM) & ZRR (FPKM) \\
\hline Os02g0756850 & Hypothetical protein & $2.36 \pm 0.31$ & 0 & $1.33 \pm 1.33$ \\
Os11g0706200 & GRAS transcription factor domain containing protein & $1.8 \pm 1.63$ & 0 & $1.98 \pm 1.91$ \\
Os12g0124700 & CDC45-like protein family protein & $1.16 \pm 1.08$ & 0 & $1.83 \pm 2.03$ \\
Os09g0412900 & Pentatricopeptide repeat domain containing protein & $1.12 \pm 0.98$ & 0 & $0.96 \pm 0.84$ \\
Os03g0140300 & Conserved hypothetical protein & $0.99 \pm 1.07$ & 0 & $0.62 \pm 0.54$ \\
Os04g0277400 & Membrane bound O-acyl transferase, MBOAT family protein & $0.84 \pm 0.71$ & 0 & $1.14 \pm 1.09$ \\
Os10g0328700 & Tetratricopeptide-like helical domain containing protein & $0.58 \pm 0.47$ & 0 & $0.39 \pm 0.34$ \\
Os07g0172600 & Pentatricopeptide repeat domain containing protein & $0.55 \pm 0.58$ & 0 & $0.67 \pm 0.63$ \\
Os01g0163000 & Leucine-rich repeat, N-terminal domain containing protein & $0.46 \pm 0.1$ & 0 & $0.4 \pm 0.38$ \\
Os03g0821700 & Pentatricopeptide repeat domain containing protein & $0.45 \pm 0.15$ & 0 & $0.53 \pm 0.19$ \\
Os02g0621600 & Similar to OSIGBa0157K09-H0214G12.24 protein & $0.44 \pm 0.59$ & 0 & $0.62 \pm 0.4$ \\
Os11g0133500 & Serine/threonine protein kinase-related domain containing protein & $0.35 \pm 0.31$ & 0 & $1.17 \pm 1$ \\
Os12g0585300 & Cyclin-like F-box domain containing protein & $1.1 \pm 0.92$ & 0 & $0.01 \pm 0.01$ \\
Os11g0111000 & Conserved hypothetical protein & $6.31 \pm 5.39$ & $0.15 \pm 0.1$ & $1.07 \pm 1.11$ \\
Os03g0758500 & Similar to blue copper protein & & $11.47 \pm 3.69$ \\
\hline
\end{tabular}

Os03g0191900, Os06g0639800, and Os06g0131300) were randomly selected and investigated by qRT-PCR. The expression patterns of these genes under $\mathrm{Zn}$ deficiency and recovery were similar to the results of RNA-seq, with the exception of Os06g0131300 (Fig. 5). Significant expression changes of $0 s 06 g 0131300$ in roots under $\mathrm{Zn}$ deficiency and recovery could not be observed by qRT-PCR, but its expression was found to be repressed by $\mathrm{Zn}$ deficiency in shoots as observed by qRT-PCR. The expression levels of Os03g0191900 in shoots could not be detected by qRT-PCR, which is consistent with the low FPKM value in shoots as revealed by RNA-seq (Fig. 5). These results suggest that the data of small RNA sequencing and mRNA sequencing obtained in this study is reliable.

We also analyzed the expression of several potential target genes of Zn-responsive miRNAs by qRT-PCR. The potential target genes of miR397b-5p showed differential responses to Zn deficiency; OsLAC7 (Os01g0850550) and OsLAC9 (Os01g0850800) were repressed by $\mathrm{Zn}$ deficiency in roots, which is contrary to the expression of miR397b5p; OsLAC7 was induced by $\mathrm{Zn}$ deficiency and repressed by $\mathrm{Zn}$ resupply in shoots (Fig. 6a). OsCDS2, the potential target gene of miR398a, was found to be repressed by $\mathrm{Zn}$ deficiency in roots, which is contrary to the expression of miR398a (Fig. 6b). The potential targets of miR408-3p also showed differential responses to $\mathrm{Zn}$ deficiency and $\mathrm{Zn}$ resupply, suggesting their different functions in $\mathrm{Zn}$ deficiency response. OsUCL16 (Os06g0218600) was upregulated by $\mathrm{Zn}$ deficiency and down-regulated by $\mathrm{Zn}$ resupply; OsUCL30 (Os08g0482700) was down-regulated by $\mathrm{Zn}$ deficiency in roots; OsORC6 (Os07g0628600) was down-regulated by $\mathrm{Zn}$ deficiency in both roots and shoots (Fig. 6c).

\section{Discussion \\ Identification of DEGs in response to $\mathrm{Zn}$ deficiency and recovery}

In this study, a total of 569 loci were found to be responsive to $\mathrm{Zn}$ deficiency and/or $\mathrm{Zn}$ resupply; 360 of them were responsive to $\mathrm{Zn}$ deficiency in roots and/or shoots, and 316 of them were responsive to $\mathrm{Zn}$ resupply in roots and/or shoots (Fig. 2). By comparing with earlier studies [24], 49 of the DEGs were reported to be responsive to $\mathrm{Zn}$ deficiency and/or $\mathrm{Zn}$ resupply (Additional file 1: Table S14). Five of the common DEGs are putative $\mathrm{Zn}$ transporters, and three of the common DEGs are metallothionein-like proteins, which are implicated in $\mathrm{Zn}$ homeostasis [7, 60]. In addition, 97 DEGs were found to be recovered by $\mathrm{Zn}$ resupply treatment in shoots and/or roots (Tables 1 and 2), suggesting their specific responses to $\mathrm{Zn}$ deficiency. These DEGs were enriched in GO terms of cellular metabolic process, primary metabolic process and biosynthetic process (Additional file 2: Figure S8), suggesting that these processes are affected by $\mathrm{Zn}$ deficiency and can be recovered by $\mathrm{Zn}$ resupply. Four of the DEGs (Os03g0108300, Os10g0528400, Os12g0570700, Os12g0571000) were also reported to be recovered by $\mathrm{Zn}$ resupply [24].

Twelve DEGs were predicted to be targeted by $10 \mathrm{Zn}$ responsive miRNAs, and half of them showed a differential expression with miRNAs under Zn deficiency and/or $\mathrm{Zn}$ resupply (Table 4), suggesting the interactions 


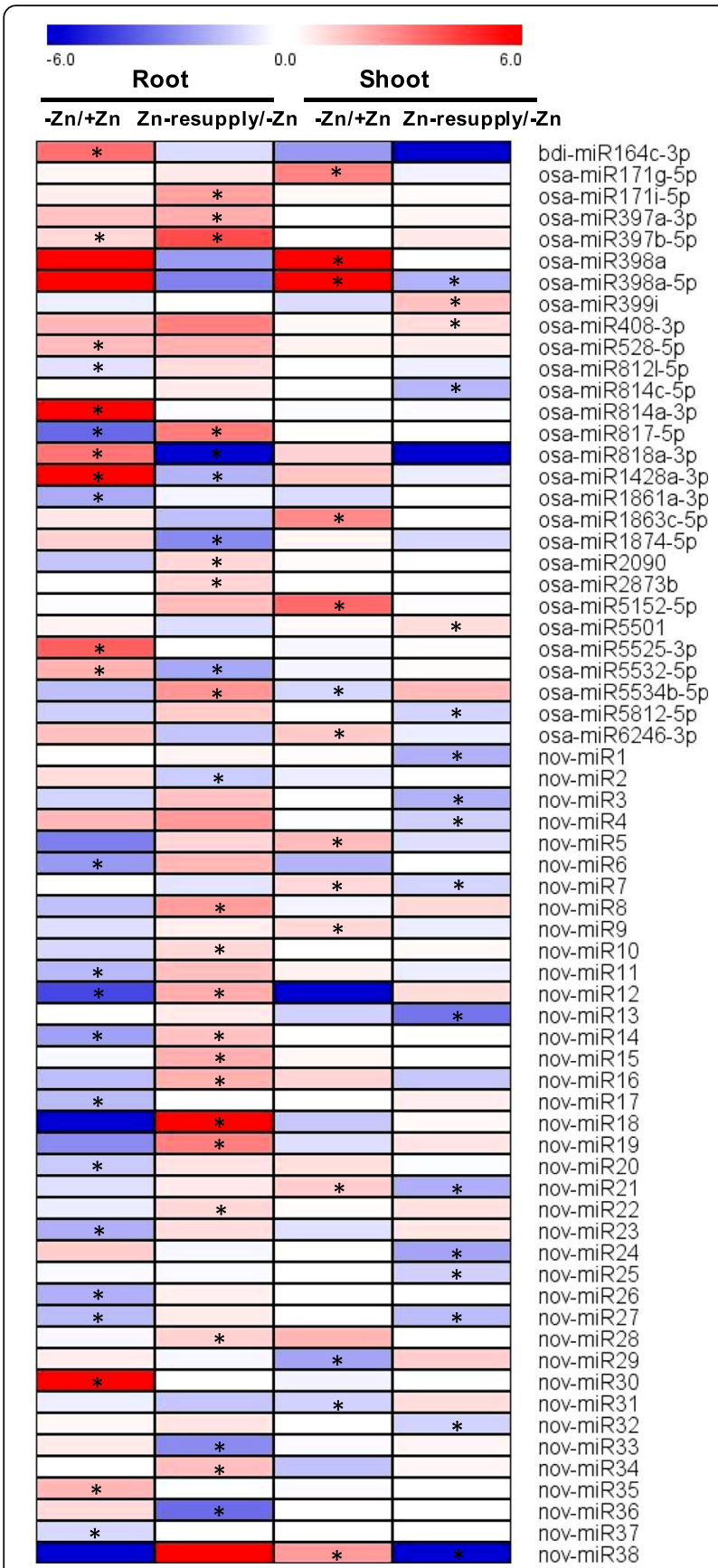

Fig. 3 Heatmap representation for expression profiles of miRNAs in response to $14 \mathrm{~d}$ of $\mathrm{Zn}$ deprivation and/or $3 \mathrm{~d}$ of $\mathrm{Zn}$ resupply in the roots and shoots. The intensities of the color represent the relative magnitude of fold changes in log2 values according to small RNA high-throughput sequencing data. The asterisks indicate significantly differentially expressed miRNAs with an absolute fold change $\geq 2$ and $P$-value $\leq 0.05$. Red color indicates induction, blue color indicates repression.

between miRNAs and their potential target genes. However, this cannot exclude the responsiveness of other potential target genes of Zn-responsive miRNAs. As revealed by qRT-PCR, several potential target genes of
Table 3 The validated target genes of some $\mathrm{Zn}$-responsive miRNAs

\begin{tabular}{|c|c|c|c|}
\hline miRNA & Target gene & $\begin{array}{l}\text { Target gene } \\
\text { annotation }\end{array}$ & Potential function \\
\hline \multirow[t]{4}{*}{$\begin{array}{l}\text { osa- } \\
\text { miR398a }\end{array}$} & Os07g0665200 & $\begin{array}{l}\text { Cu/Zn- } \\
\text { superoxidase } \\
\text { dismutase2/CSD2 }\end{array}$ & \multirow[t]{4}{*}{$\begin{array}{l}\text { Stress tolerance, } \\
\text { antioxidant defense, } \\
\text { copper homeostasis }\end{array}$} \\
\hline & Os03g0351500 & $\begin{array}{l}\mathrm{Cu} / \mathrm{Zn} \text { - } \\
\text { superoxidase } \\
\text { dismutase1/CSD1 }\end{array}$ & \\
\hline & Os11g0203300 & $\begin{array}{l}\text { Superoxide } \\
\text { dismutaseX/SODX }\end{array}$ & \\
\hline & Os04g0573200 & $\begin{array}{l}\text { Copper chaperone } \\
\text { for superoxide } \\
\text { dismutase/CCSD }\end{array}$ & \\
\hline \multirow{9}{*}{$\begin{array}{l}\text { osa- } \\
\text { miR408- } \\
3 p\end{array}$} & Os08g0482700 & $\begin{array}{l}\text { Uclacyanin-like } \\
\text { protein UCL30 }\end{array}$ & \multirow{9}{*}{$\begin{array}{l}\text { Stress tolerance, } \\
\text { photosynthesis, copper } \\
\text { homeostasis, }\end{array}$} \\
\hline & Os03g0709100 & $\begin{array}{l}\text { Uclacyanin-like } \\
\text { protein UCL8 }\end{array}$ & \\
\hline & Os04g0545600 & $\begin{array}{l}\text { Uclacyanin-like } \\
\text { protein UCL15 }\end{array}$ & \\
\hline & Os06g0218600 & $\begin{array}{l}\text { Uclacyanin-like } \\
\text { protein UCL16 }\end{array}$ & \\
\hline & Os02g0653200 & $\begin{array}{l}\text { Plantacyanin like } \\
\text { 2/Uclacyanin-like } \\
\text { protein UCL4 }\end{array}$ & \\
\hline & Os02g0731400 & $\begin{array}{l}\text { Plantacyanin-like } \\
\text { 3/Uclacyanin-like } \\
\text { protein UCL5 }\end{array}$ & \\
\hline & Os02g0758800 & $\begin{array}{l}\text { Plantacyanin-like } \\
\text { 4/Uclacyanin-like } \\
\text { protein UCL6 }\end{array}$ & \\
\hline & Os01g0827300 & Laccase 3/LAC3 & \\
\hline & Os03g0297900 & Laccase 12/LAC12 & \\
\hline \multirow{5}{*}{$\begin{array}{l}\text { osa- } \\
\text { miR528- } \\
5 p\end{array}$} & Os06g0567900 & $\begin{array}{l}\text { Ascorbate oxidase } \\
2\end{array}$ & \multirow{5}{*}{$\begin{array}{l}\text { Reactive oxygen species } \\
\text { homeostasis, stress } \\
\text { tolerance, copper } \\
\text { homeostasis, } \\
\text { strigolactone signal } \\
\text { perception }\end{array}$} \\
\hline & Os08g0137400 & $\begin{array}{l}\text { Uclacyanin-like } \\
\text { protein UCL23 }\end{array}$ & \\
\hline & Os07g0570550 & $\begin{array}{l}\text { Cupredoxin } \\
\text { domain } \\
\text { containing protein }\end{array}$ & \\
\hline & Os06g0154200 & $\begin{array}{l}\text { F-box/LRR-repeat } \\
\text { MAX2 homolog/ } \\
\text { DWARF3 }\end{array}$ & \\
\hline & Os08g0561700 & $\begin{array}{l}\text { Superoxide } \\
\text { dismutase 4/CSD4 }\end{array}$ & \\
\hline $\begin{array}{l}\text { osa- } \\
\text { miR397b- } \\
5 p\end{array}$ & Os05g0458600 & Laccase 15/LAC15 & $\begin{array}{l}\text { Copper homeostasis, } \\
\text { lignin biosynthesis, } \\
\text { brassinosteroid } \\
\text { response }\end{array}$ \\
\hline
\end{tabular}

miR397b, miR408 and miR398a were also found to be induced or repressed by $\mathrm{Zn}$ deficiency and/or $\mathrm{Zn}$ resupply (Table 3, Fig. 5b). The number of DEGs potentially regulated by Zn-responsive miRNAs in this study is far below our expectation. One of the possible reasons is that the accepted standard used for the definition of 
DEGs may miss some interactions between miRNAs and their potential target genes, and more interaction pairs may be identified by lowering the threshold.

\section{miRNAs potentially involved in the regulation of $\mathrm{Zn}$ deficiency response in rice}

miRNAs have been demonstrated to be involved in signaling and regulation of nutrient stress responses, like nitrogen deficiency, phosphate starvation, sulfate deprivation, and $\mathrm{Cu}$ deficiency [38-40, 61, 62]. In this study, we analyzed the miRNA expression profilings under $\mathrm{Zn}$ deficiency and $\mathrm{Zn}$ resupply, and 68 miRNAs were found to be responsive to $\mathrm{Zn}$ deficiency and/or $\mathrm{Zn}$ resupply in rice (Fig. 3). Some of the miRNA families were also found to be responsive to $\mathrm{Zn}$ deficiency in Sorghum bicolor, like miR171, miR398, miR399, miR408, and miR528 [2], suggesting their conserved roles in plant response to $\mathrm{Zn}$ deficiency.

Among the Zn-responsive miRNAs, 38 (56\%) of them were novel miRNAs. Most of these novel miRNAs (36/38) are encoded by a single locus (Additional file 1: Table S12), suggesting their recent evolutionary origin. Most of the novel miRNAs (30/38) contained an opposite strand (miRNA*) that can be detected by small RNA sequencing, and most of the novel miRNAs (28/38) were $24 \mathrm{nt}$ in length (Additional file 1: Table S12; Additional file 2: Figure S5). In rice, a proportion of pri-miRNAs can be processed into canonical miRNAs (21 nt) and long miRNAs $(24 \mathrm{nt})$ by Dicer-like 1 (DCL1) and DCL3, respectively $[63,64]$. The $24 \mathrm{nt}$ long miRNAs are sorted into the effector Argonaute 4 (AGO4) and possibly direct DNA methylation by base pairing with target loci-derived transcripts $[26,63]$. DNA methylation modulates gene expression and represses the transcription and movement of transposable elements. The expression of some key nutrient stress-responsive genes has been suggested to be regulated by DNA methylation under specific nutrient stress conditions [65]. In this study, many of the $\mathrm{Zn}$-responsive novel miRNAs (20/38) were down-regulated by Zn deficiency and/or up-regulated by Zn resupply (Fig. 3). The potential target genes of these $\mathrm{Zn}$-responsive novel miRNAs encode various kinds of proteins, such as transcription factors, transporters, protein kinases, Zn-containing protein, and oxidoreductases (Additional file 1: Table S13). Whether these recently-evolved and possibly species-specific Zn-responsive novel miRNAs are associated with acclimation to submergence and low $\mathrm{Zn}$ conditions in rice, and are involved in epigenetic regulation of $\mathrm{Zn}$ deficiency response deserve further investigations.

\section{Potential role of miRNAs in $\mathrm{Cu}-\mathrm{Zn}$ interaction in plants}

Among the $\mathrm{Zn}$-responsive miRNAs identified in this study, some of the miRNA families were previously documented to be responsive to $\mathrm{Cu}$ deficiency, such as miR397, miR398, and miR408, which are all induced by
$\mathrm{Cu}$ deficiency and their target genes encode various $\mathrm{Cu}$ containing proteins [39]. In rice, nineteen potential target genes of the $\mathrm{Cu} / \mathrm{Zn}$-responsive miRNAs have been validated, most of them encode $\mathrm{Cu}$-containing proteins, like CSDs, laccases, plantacyanin like proteins, and uclacyanin-like proteins (Table 3). The potential target genes of Zn-responsive miRNAs were significantly enriched in the $\mathrm{GO}$ terms of $\mathrm{Cu}$ ion binding and laccase activity (Fig. 4). These results suggest the involvement of miRNAs in the interaction between $\mathrm{Cu}$ and $\mathrm{Zn}$ nutrition in plants.

It has been demonstrated that $\mathrm{Cu}$ and $\mathrm{Zn}$ could interact in several ways: $\mathrm{Cu}$ competitively inhibits $\mathrm{Zn}$ absorption, $\mathrm{Zn}$ strongly depresses $\mathrm{Cu}$ absorption, and $\mathrm{Cu}$ affects the redistribution of $\mathrm{Zn}$ within plants [66, 67]. The uptakes of $\mathrm{Cu}$ and iron $(\mathrm{Fe})$ were found to be increased by $\mathrm{Zn}$ deficiency in rice seedlings [68]. In this study, miR398 and miR528 were found to be induced by $\mathrm{Zn}$ deficiency. The induction of miR398 and miR528 could depress the expressions of Zn-containing target gene $C S D$ s $[2,50]$, which can be functionally replaced by Fe superoxide dismutase and Mn superoxide dismutase, thus further allow the allocation of limited $\mathrm{Zn}$ to other essential $\mathrm{Zn}$-containing proteins in order to adapt to the low $\mathrm{Zn}$ environment. The miRNA-mediated regulation of $\mathrm{Zn}$ homeostasis could be similar to that of the miRNA-mediated regulation of $\mathrm{Cu}$ homeostasis as reported previously [69, 70]. Interestingly, another two $\mathrm{Cu}$-responsive miRNAs, miR397 and miR408 were found to be induced by $\mathrm{Zn}$ resupply (Fig. 3). The induction of these two miRNAs may be a direct effect of $\mathrm{Zn}$ resupply, and may also be an indirect effect of Zn-resupplyinduced antagonism on $\mathrm{Cu}$ nutrition. The primary transcripts of miR397b and miR408 were found to be repressed by $\mathrm{Zn}$ deficiency (Fig. 5). Whether the repressions of miR397b and miR408 would be associated with the $\mathrm{Zn}$ deficiency-induced $\mathrm{Cu}$ accumulation in plant tissues deserve further studies.

\section{miRNA-mediated oxidative stress in response to $\mathrm{Zn}$ deficiency}

Zn deficiency can interfere with membrane-bound NADPH oxidase producing ROS and further cause oxidative damage to critical cell compounds by the excessive ROS, which is a major factor affecting plant growth under Zn deficiency [11]. It has been reported that $\mathrm{Zn}$ deficiency causes cellular damage in leaves and roots and maintaining a higher ROS defense level is associated with reduced cellular damage in rice leaves $[2,71,72]$. In this study, GO terms of oxidoreductase activity was significantly enriched in the potential target genes of Zn-responsive miRNAs (Fig. 4). miR398 was reported to be involved in the regulation of oxidative stress response by silencing the expression of CSD1 and CSD2 in Arabidopsis [73]. Here, miR398 was induced by $\mathrm{Zn}$ 


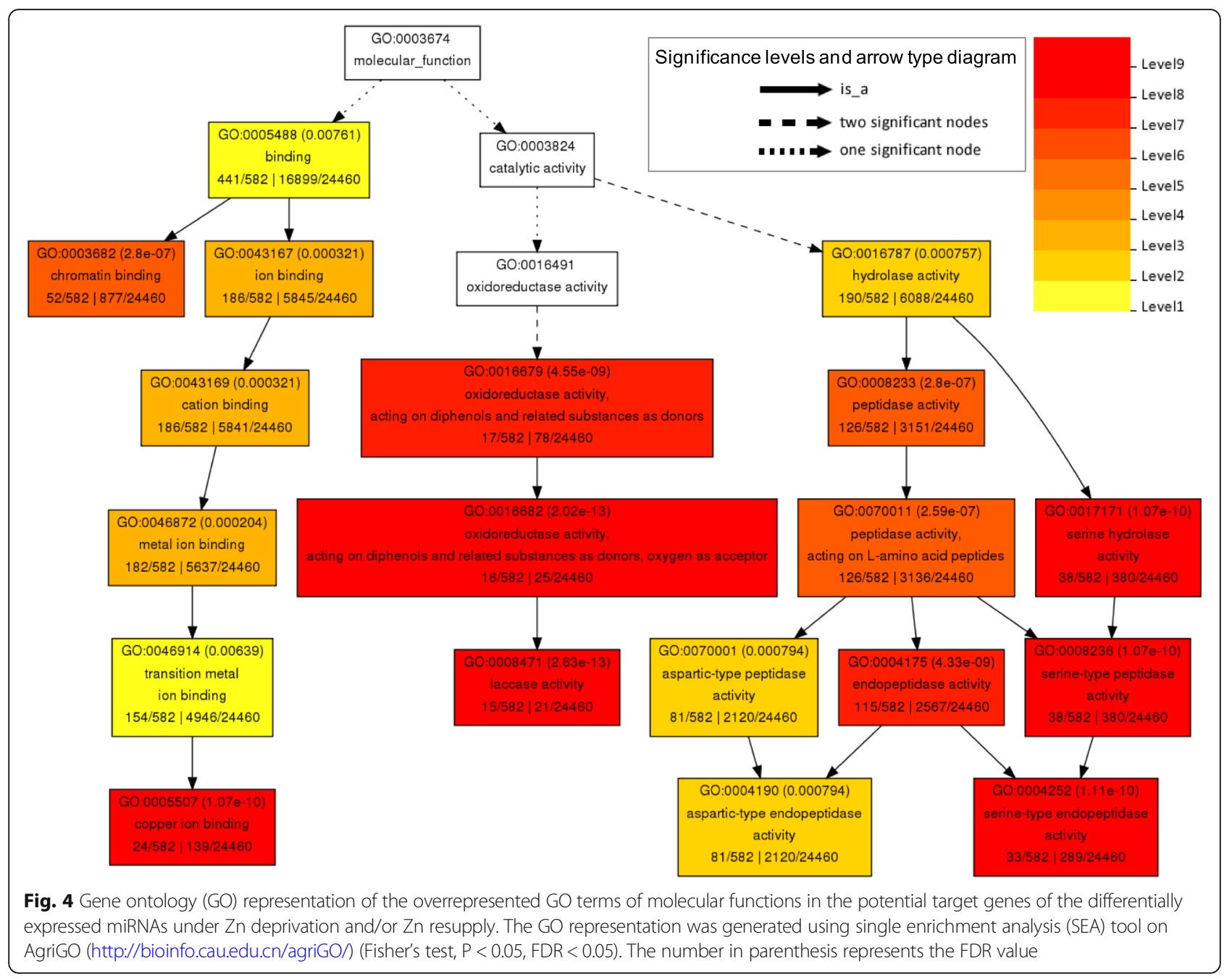

Table 4 DEGs under Zn deficiency and/or Zn resupply that are potential targets of Zn-responsive miRNAs

\begin{tabular}{|c|c|c|c|c|}
\hline miRNA & miRNA response to $\mathrm{Zn}$ & Potential target & Target description & Target response to $\mathrm{Zn}$ \\
\hline osa-miR171g-5p & $-Z n$ up & Os05g0278500 & Transferase family protein & - Zn up \\
\hline \multirow[t]{2}{*}{ osa-miR397b-5p } & Zn resupply up & Os03g0273200 & LACCASE 11 & $-Z n$ up \\
\hline & & Os12g0258700 & LACCASE 29 & Zn resupply down \\
\hline osa-miR398a-5p & -Zn up, Zn resupply down & Os07g0213800 & Similar to Allergenic protein & -Zn down \\
\hline osa-miR528-5p & $-Z n$ up & Os06g0154200 & Similar to F-box/LRR-repeat MAX2 homolog & $-Z n$ up \\
\hline nov-miR1 & Zn resupply down & Os08g0107800 & Pentatricopeptide repeat domain containing protein & Zn resupply down \\
\hline nov-miR4 & Zn resupply down & Os01g0358700 & - & Zn resupply up \\
\hline nov-miR6 & -Zn down & Os04g0623901 & Non-protein coding transcript & $-Z n$ up \\
\hline \multirow[t]{2}{*}{ nov-miR23 } & - Zn down & Os06g0505501 & Non-protein coding transcript & -Zn down, Zn resupply up \\
\hline & & Os01g0923900 & Cyclin-like F-box domain containing protein & Zn resupply down \\
\hline nov-miR26 & $-Z n$ down & Os11g0684700 & Similar to NB-ARC domain containing protein & Zn resupply up \\
\hline nov-miR38 & -Zn up, Zn resupply down & Os04g0304400 & Similar to MADS-box protein AGL16-\| & -Zn up, Zn resupply down \\
\hline
\end{tabular}




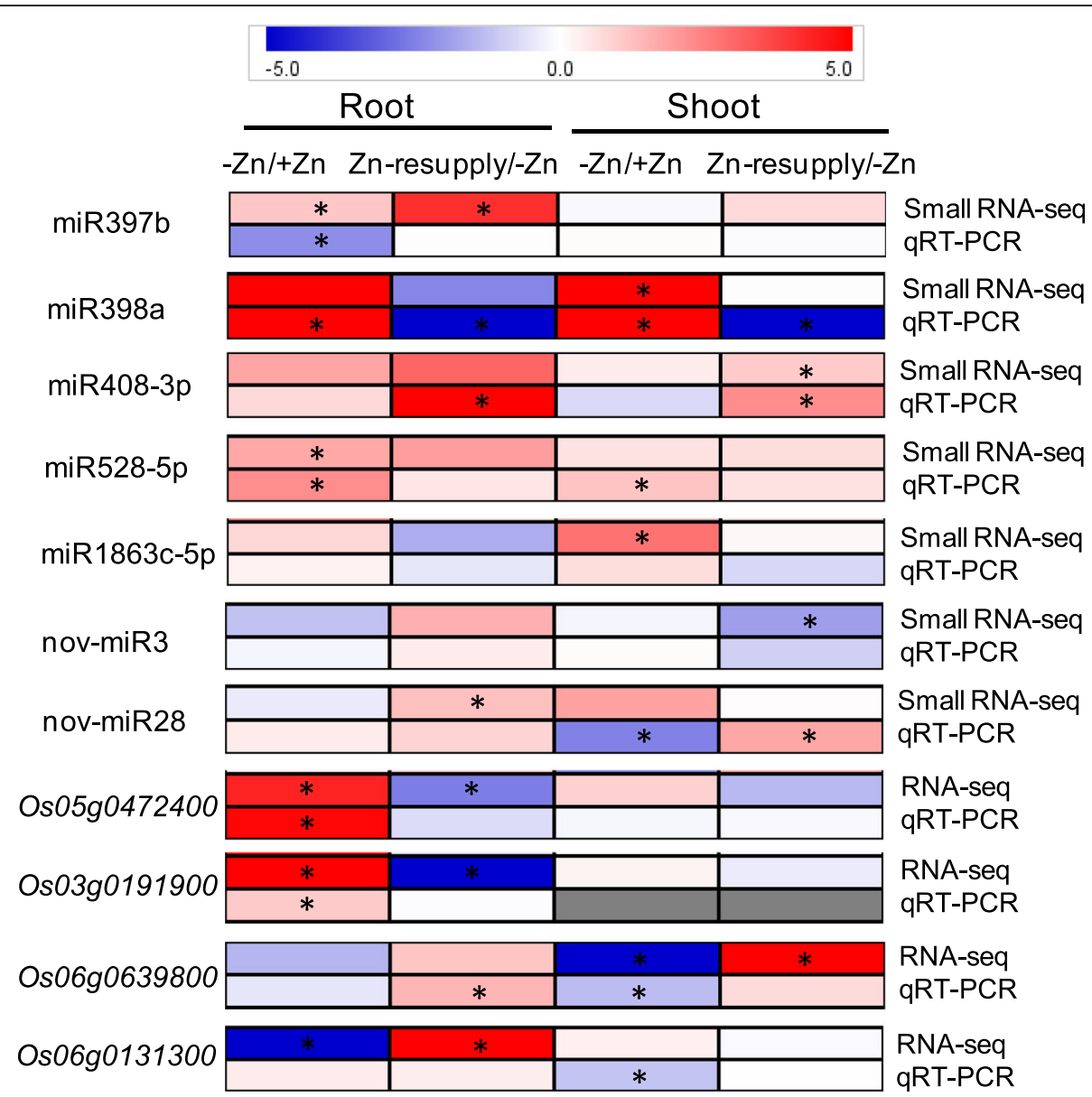

Fig. 5 Heatmap of the expression of differentially expressed miRNAs and DEGs revealed by deep sequencing and qRT-PCR. Seven miRNAs and four DEGs were randomly selected and analyzed by qRT-PCR. The primary transcripts of miRNAs (pri-miRNAs) were analyzed to for miRNA expression validation. The intensities of the color represent the fold changes in log2 values according to qRT-PCR results of three replicates. The asterisks indicate an absolute fold change $\geq 2$ and P-value $\leq 0.05$. Red color indicates induction, blue color indicates repression, and gray color indicates no expression detected

deficiency in the shoots. The induction of miR398 could repress the expression of its target genes (CSDs, SODX, CCSD) and then promote the accumulation of ROS. miR398 was also reported to be induced by other stresses, such as salt, heat and infection of blast fungus Magnaporthe oryzae [29, 52]. The induction of miR398 has been suggested to be required for thermotolerance in Arabidopsis and resistance to blast disease in rice $[51,52]$. Another Zn-responsive miRNA, miR528 was also reported to be involved in the regulation of ROS accumulation [55, 56]. One of the target gene of miR528, CSD4 (Os08g0561700) is possibly involved in ROS scavenging. Another target gene of miR528, Os06g0567900, encoding a L-ascorbate oxidase (AO), is involved in producing ROS by regulating the redox state of the apoplast by oxidizing apoplastic L-ascorbate acid [56]. Overexpression of osa-miR528 can decrease AO activity and increase ROS scavenging and further improve plant tolerance to salt and nitrogen deficiency stresses in creeping bentgrass [55]. In this study, miR528 was found to be induced by $\mathrm{Zn}$ deficiency, suggesting its role in balancing ROS accumulation and scavenging under $\mathrm{Zn}$ stress.

\section{Conclusions}

The present study is the first attempt to integrate global miRNA and mRNA expression profiles to identify regulatory miRNA/target modules in response to $\mathrm{Zn}$ deficiency and recovery in rice. A set of 68 miRNAs including 38 novel miRNAs and five $\mathrm{Cu}$-responsive miRNAs were identified to be differentially expressed. At least 12 potential target genes of $\mathrm{Zn}$-responsive miRNAs were found to be altered by $\mathrm{Zn}$ deficiency and recovery. Ninety-seven Zn-deficiency-responsive genes were found to be recovered by $\mathrm{Zn}$ resupply. This global analysis of the rice miRNAome and transcriptome in responses to $\mathrm{Zn}$ deficiency and recovery identifies candidate miRNAs and genes that can be further characterized to increase our understanding of the molecular mechanisms of Zn deficiency response. The identified differentially expressed miRNA/target modules and genes can also be considered as 

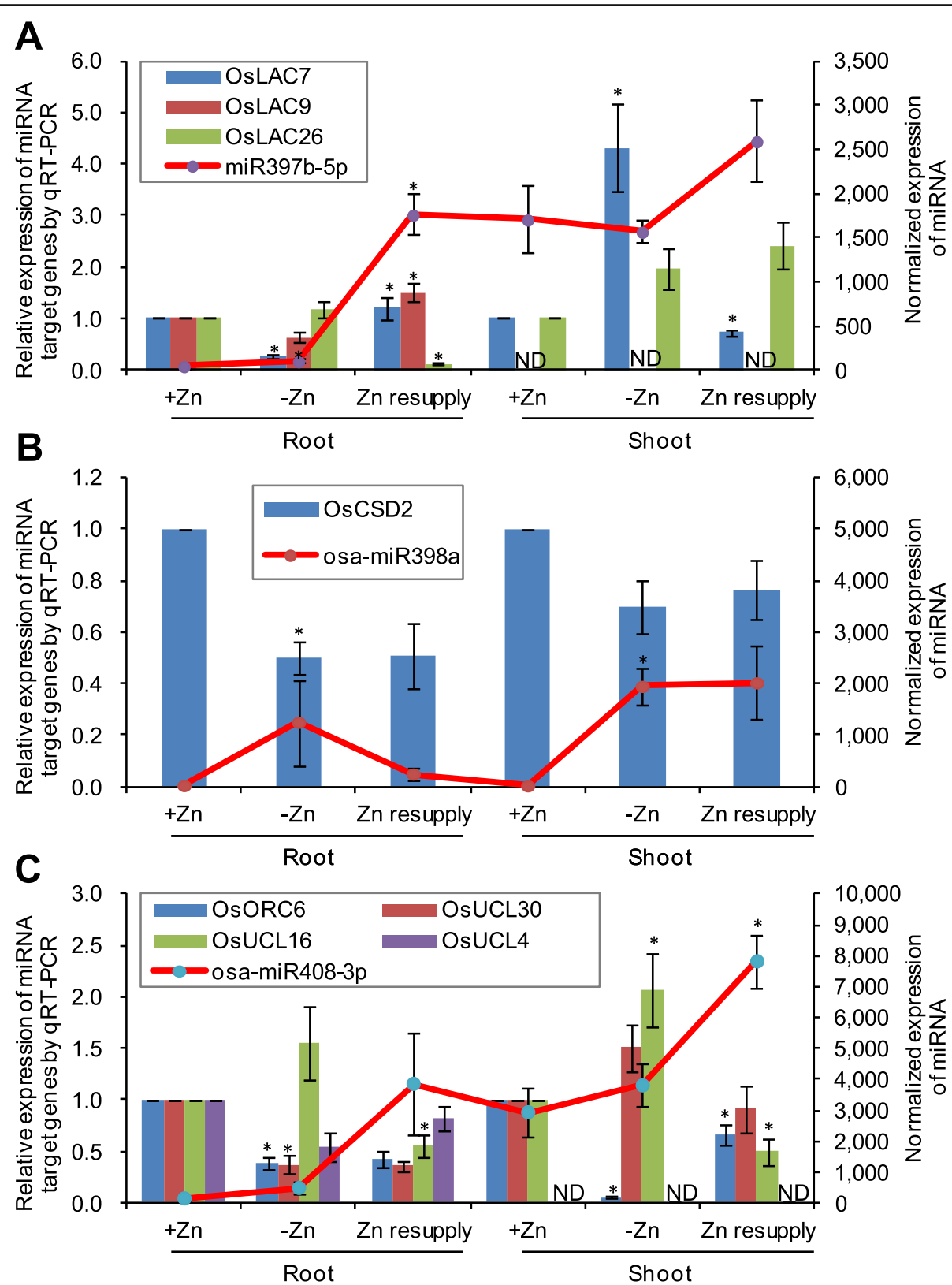

Fig. 6 The relative expression levels of three Zn-responsive miRNAs and their potential target genes. The relative expression of potential target genes of miR397b-5p (a), miR398a (b), and miR408-3p (c) were analyzed by qRT-PCR. The normalized expression levels of miRNAs revealed by small RNA sequencing were shown with line charts. The expression level of $+Z n$ control in roots and shoots was normalized to one. Error bar represents standard deviation of three biological replicates. The asterisk above error bar indicates an absolute fold change $\geq 2(-\mathrm{Zn} /+\mathrm{Zn}$, or $\mathrm{Zn}$ resupply/-Zn) and P-value $\leq 0.05$. ND means "not detected"

candidates for improving $\mathrm{Zn}$ deficiency tolerance by genetic engineering approaches.

\section{Methods}

\section{Plant material and growth conditions}

Seeds of the rice (Oryza sativa L. ssp. japonica cv. Nipponbare) from our own lab were surface sterilized in $10 \%(\mathrm{v} / \mathrm{v}) \mathrm{H}_{2} \mathrm{O}_{2}$ for $20 \mathrm{~min}$ and rinsed with sterile water [74]. Seeds were then transferred to seedling trays floating on sterile water for germination. After growing in the sterile water for 10 days, seedlings were transferred to a plastic container with $2.5 \mathrm{~L}$ Yoshida solution [75]. After growing in the nutrient solution (with $1.5 \mu \mathrm{M}$ $\mathrm{ZnSO}_{4}$ ) for 1 week, uniform seedlings were used for $\mathrm{Zn}$ deficiency $(-\mathrm{Zn})$ treatment. For $-\mathrm{Zn}$ treatment, no $\mathrm{ZnSO}_{4}$ was added to the nutrient solution. The fresh nutrient solution was replenished every 2 day, and the $\mathrm{pH}$ was adjusted to 5.6. Plants were grown in a growth 
chamber under controlled conditions. The light intensity was approximately $180 \mu \mathrm{mol} \mathrm{m}^{-2} \mathrm{~s}^{-1}$ at shoot height with a day/night cycle of $16 \mathrm{~h} / 8 \mathrm{~h}$ at $26^{\circ} \mathrm{C} / 24^{\circ} \mathrm{C}$. The relative humidity was $50 \%$. Roots and shoots of rice seedlings were collected after $\mathrm{Zn}$-deficient treatment for 2 weeks. For Zn-resupply treatment, Zn-deficient seedlings were transferred to normal nutrient solution containing $1.5 \mu \mathrm{M} \mathrm{ZnSO}$. for 3 days. After Zn-resupply treatment, roots and shoots were collected for analyses at the same time point as collecting the $\mathrm{Zn}$-deficient samples (4 hours after illumination).

\section{Zn content determination}

Zn content was analyzed as described previously $[23,76]$. Plant tissues were collected and dried in an oven at $80^{\circ} \mathrm{C}$ for 3 days. The roots were rinsed with deionized water for three times before collection. The dried roots or shoots were ground, and about $0.10 \mathrm{~g}$ sample was used for analysis. After digestion with $\mathrm{HNO}_{3} / \mathrm{HClO}_{4}(4: 1, \mathrm{v} / \mathrm{v})$ at $180^{\circ} \mathrm{C}$ for $4 \mathrm{~h}$, the solution was diluted five times with $1 \% \mathrm{HNO}_{3}$, and then the concentration of $\mathrm{Zn}$ was determined by Inductively Coupled Plasma Mass Spectroscopy (Perkin-Elmer NexION 300X, Waltham, MA).

\section{cDNA library construction and RNA sequencing}

Rice shoots and roots were collected after $\mathrm{Zn}$-deficiency and $\mathrm{Zn}$-resupply treatments. Three rice seedlings were collected and mixed together as one sample. Eighteen samples (Zn plus shoot, ZPS; Zn minus shoot, ZMS; Zn plus root, ZPR; Zn minus root, ZMR; Zn resupply shoot, ZRS; Zn resupply root, ZRR, each with three biological replicates) were harvested for RNA library construction and sequencing. Total RNA was extracted using Trizol reagent (Invitrogen, CA, USA), and the quantity and quality were analyzed by Bioanalyzer 2100 and RNA 6000 Nano LabChip Kit (Agilent, CA, USA). The RIN value (RNA integrity number) of all RNA samples were more than 8.0. Ten $\mu \mathrm{g}$ of total RNA of each sample was subjected to isolate Poly (A) mRNA with poly-T oligoattached magnetic beads (Invitrogen, Carlsbad, CA). After purification, the mRNA is fragmented into small pieces using divalent cations under elevated temperature. The cleaved RNA fragments were reverse-transcribed to create cDNA libraries according to the instructions of the mRNA-Seq sample preparation kit (Illumina, San Diego, USA). The average insert size of the paired-end libraries was $300 \pm 50 \mathrm{bp}$. The paired-end sequencing was performed on an Illumina Hiseq4000 at the LC-BIO (Hangzhou, China). The RNA-seq datasets of this study were deposited in NCBI's Gene Expression Omnibus and are accessible through GEO accession number GSE130980 (https://www.ncbi.nlm.nih.gov/geo/query/ acc.cgi?acc=GSE130980).

\section{Mapping of RNA-seq reads and identification of differentially expressed genes}

The initial base calling and quality filtering of the reads generated with the Illumina analysis pipeline (Fastq format) were conducted using a custom Perl script and the default parameters of the Illumina pipeline (http://www. illumina.com). Additional filtering for poor-quality bases was performed using the FASTX-toolkit available in the FastQC software package (http://www.bioinformatics. babraham.ac.uk/projects/fastqc/). The rice reference genome (version IRGSP-1.0) (https://rapdb.dna.affrc.go. $\mathrm{jp} /$ ) was indexed by Bowtie2 to facilitate the read mapping. The read mapping was performed using the Tophat software (version 2.1.1) package [77]. Tophat allows multiple alignments per read (up to 40) and a maximum of two mismatches when mapping the reads to the reference genome. Reads were first mapped directly to the genome using indexing and the unmapped reads were used to identify novel splicing events. The aligned read files were processed by Cufflinks to measure the relative abundances of the transcripts by using the normalized RNA-seq fragment counts. The estimated gene abundance was measured in terms of the fragments per kilobase of transcript per million mapped reads (FPKM). The DEGs between the two treatments were identified using Cuffdiff (version 2.1.1). Only the genes with a log2 fold change $\geq 1$ or $\leq-1$, and an adjusted $P$-value (FDR $\leq$ $0.05)$ were considered as significantly DEGs. The Pearson correlation was calculated and plotted using the $\mathrm{R}$ Stats package (version 3.5.0) based on the normalized counts of mRNAs of each sample.

\section{Functional annotation and gene ontology (GO) enrichment}

$\mathrm{Zn}$-deficiency responsive genes and potential target genes of miRNAs were annotated for gene ontology (GO) terms [78] and categorized into molecular function, cellular component, and biological process categories. GO term enrichment was conducted using single enrichment analysis tool on AgriGo (http://bioinfo.cau. edu.cn/agriGO/) [79]. GO category (http://geneontology. org/) with an adjusted P-value $\leq 0.05$ was regarded as significantly enriched.

\section{Construction of small RNA libraries and sequencing}

Eighteen samples (ZPS, ZMS, ZPR, ZMR, ZRS, and ZRR, each with three biological replicates) were harvested for small RNA library construction and sequencing. Total RNAs were extracted from samples using Trizol reagent (Invitrogen, Carlsbad, CA). Approximately $1.0 \mu \mathrm{g}$ of total RNA was used to prepare a small RNA library according to the instruction of TruSeq Small RNA Sample Prep Kits (Illumina, San Diego, USA). Single-end sequencing with a length of about $50 \mathrm{bp}$ was performed on an 
Illumina Hiseq2500 at the LC-BIO (Hangzhou, China). The small RNA sequencing datasets of this study were deposited in NCBI's Gene Expression Omnibus and are accessible through GEO accession number GSE131003 (https://www.ncbi.nlm.nih.gov/geo/query/acc.cgi?acc= GSE131003).

\section{Identification of miRNAs and prediction of their target genes}

The raw reads were performed on an in-house program ACGT101-miR (LC Sciences, Houston, Texas, USA) to remove adaptor sequences, low-complexity sequences, junk reads, repeat sequences, and the reads that matched the common non-coding RNA families (tRNA, rRNA, snoRNA, and snRNA) deposited in Rfam database (http://www.sanger. ac.uk/software/Rfam). Subsequently, unique sequences with length of 20-24 nucleotide (nt) were mapped to rice miRNA precursors in miRBase 22.0 by BLAST (version 2.6.0) to identify known miRNAs and novel $3 p$ - and $5 p$ - derived miRNAs. Length variation at both $3^{\prime}$ and $5^{\prime}$ ends, and one nt mismatch of the miRNA sequence for the alignment were allowed. The unique sequences mapping to rice mature miRNAs in the precursors were identified as known miRNAs. The unique sequences mapping to the opposite arm of known rice miRNA precursor hairpin were considered to be novel 5p- or 3p- derived miRNA candidates. The remaining sequences were mapped to miRNA precursors of other plant species in miRBase 22.0 (http://www.mirbase.org/) by BLAST (version 2.6.0), and the mapped pre-miRNAs were further aligned with the rice genome to determine their genomic locations. The remaining unmapped sequences were further aligned with the rice genome, and the flanking sequences with a length of 120 nt were collected for secondary structure prediction using RNAfold software (http://rna.tbi. univie.ac.at/cgi-bin/RNAfold.cgi). The criteria for novel miRNA prediction and characterization were based on previous study [80].

The abundance of each miRNA were normalized to the expression of tags per million (TPM) following the formula: normalized expression = actual miRNA count $/$ total count of clean reads $* 10^{6}$. To identify $\mathrm{Zn}$ deficiencyor $\mathrm{Zn}$ resupply- responsive miRNAs, only the miRNAs with a $\log 2$ fold change $\geq 1$ or $\leq-1$ and a $p$-value $\leq 0.05$ were considered as significantly differentially expressed miRNAs. To predict potential target genes of $\mathrm{Zn}$ responsive miRNAs, psRNATarget (a plant small RNA target analysis server) (http://plantgrn.noble.org/psRNATarget/) (V2, 2017 release) was employed based on the imperfect complementation between the sequences of miRNAs and their target genes [46].

\section{Quantitative RT-PCR analysis}

Quantitative RT-PCR (qRT-PCR) was performed on a MyiQ Single Color Real-time PCR system (Bio-Rad) as described previously [81]. qRT-PCR analysis of primary miRNA (primiRNA) were performed as described previously [59, 82]. The stem-loop sequences were used for primer design, and if no satisfactory primers could be found, stem-loop sequences were elongated by 100 bp of flanking genomic sequences on each side for primer design. Relative expression levels were normalized to that of two internal control genes OsACTIN1 (Os03g0718100) and OsUBQ2 (OsO2g0161900) using the Pfaffl method (Ratio $=\left(E_{\text {target }}\right)_{\text {target }}^{\Delta \mathrm{CT}}$ (control-sample) $/\left(E_{\text {ref }}\right)$ $\Delta \mathrm{CT}$ (control-sample) [83]. The calculated efficiency (E) of all primers was between 1.8 and 2.2. The sequences of primers are listed in Additional file 1: Table S1.

\section{Supplementary information}

Supplementary information accompanies this paper at https://doi.org/10. 1186/s12870-019-2203-2.

Additional file 1: Table S1. Primers used for quantitative RT-PCR anaIysis. Table S2. Summary of the reads from RNA sequencing in the $18 \mathrm{li}$ braries. Table S3. RNA-seq analysis of rice shoot and root samples under $Z n$ deprivation and $Z n$ resupply. Table S4. List of differentially expressed loci in response to $14 \mathrm{~d}$ of $\mathrm{Zn}$ deprivation in rice shoots. Table S5. List of differentially expressed loci in response to $14 \mathrm{~d}$ of $\mathrm{Zn}$ deprivation in rice roots. Table S6. List of differentially expressed loci in response to $3 \mathrm{~d}$ of $\mathrm{Zn}$ resupply in rice shoots. Table $\mathbf{S 7}$. List of differentially expressed loci in response to $3 \mathrm{~d}$ of $\mathrm{Zn}$ resupply in rice roots. Table S8. GO representation of the over-represented GO terms in the DEGs regulated by $\mathrm{Zn}$ deprivation and/or Zn resupply. Table S9. Overview of small RNA sequencing data of the 18 libraries. Table S10. Counts and length distribution of total sRNAs and unique sRNAs in this study. Table S11. Summary of the detected known and predicted miRNAs in this study. Table S12. Differentially expressed miRNAs in response to $14 \mathrm{~d}$ of $Z \mathrm{n}$ deprivation and/or $3 \mathrm{~d}$ of $\mathrm{Zn}$ resupply in the roots and shoots. Table S13. Potential target genes of the $\mathbf{Z n}$-responsive miRNAs. Table S14. Common DEGs identified in this study and earlier studies.

Additional file 2: Figure S1. Pearson's correlation (R-value) of three biological replicates of shoot and root samples for RNA sequencing under control, Zn deficiency, and Zn resupply conditions. Zn plus shoot, ZPS; Zn minus shoot, ZMS; Zn plus root, ZPR; Zn minus root, ZMR; Zn resupply shoot, ZRS; Zn resupply root, ZRR. Figure S2. Length distribution of the small RNAs from the small RNA sequencing data in the six samples. Each bar indicates the mean \pm SD of three biological replicates. Figure S3. Pearson's correlation (R-value) of three biological replicates of shoot and root samples for small RNA high-throughput sequencing under control, Zn deficiency, and Zn resupply conditions. Figure S4. Venn diagram representing the overlap of the $\mathrm{Zn}$-deficiency- and Zn-resupply- responsive miRNAs (a, known and novel miRNAs; $b$, novel miRNAs) in roots and shoots. Figure S5. Predicted secondary structures of 38 Zn-responsive novel miRNAs identified in this study. The red lines indicate the mature miRNA sequences that were found to be differentially expressed under $\mathrm{Zn}$ deficiency and/or $\mathrm{Zn}$ resupply. The blue lines indicate the miRNA* sequences that were detected by the small RNA sequencing. If no blue line was indicated, it means that no miRNA* sequences were detected by the small RNA sequencing. Figure S6. Gene ontology (GO) representation of the overrepresented $\mathrm{GO}$ terms of biological processes in the potential target genes of the differentially expressed miRNAs under $\mathrm{Zn}$ deficiency and/or Zn resupply. The GO representation was generated using single enrichment analysis (SEA) tool on AgriGO (http://bioinfo.cau.edu.cn/agriGO/) (Fisher's test, $P<0.05, F D R<0.05)$. The number in parenthesis represents the FDR value. Figure S7. Gene ontology (GO) representation of the over represented $\mathrm{GO}$ terms of cellular component in the potential target genes of the differentially expressed miRNAs under Zn deficiency and/or Zn resupply. The GO representation was generated using single enrichment analysis (SEA) tool on AgriGO (http://bioinfo.cau.edu.cn/agriGO/) 
(Fisher's test, $P<0.05, F D R<0.05)$. The number in parenthesis represents the FDR value. Figure S8. Gene ontology (GO) representation of the overrepresented $\mathrm{GO}$ terms of biological process in the DEGs recovered by $\mathrm{Zn}$ resupply in roots and shoots. The $\mathrm{GO}$ representation was generated using single enrichment analysis (SEA) tool on AgriGO (http://bioinfo.cau.edu.cn/agriGO/) (Fisher's test, $\mathrm{P}<0.05, \mathrm{FDR}<0.05$ ). The number in parenthesis represents the FDR value.

\section{Abbreviations}

AGO4: Argonaute 4; AO: L-ascorbate oxidase; bZIP: Basic leucine zipper; CCSD: Copper chaperone for superoxide dismutase; CSD: Copper/zinc superoxide dismutase; Cu: Copper; DCL1: Dicer-like 1; DEG: Differentially expressed gene; Fe: Iron; FPKM: Fragments per kilobase of transcript per million mapped reads; GA: Gibberellin; GO: Gene ontology; H3K9: Histone H3 lysine 9; miRNA: microRNA; NAS: Nicotianamine synthase; qRT-

PCR: Quantitative RT-PCR; RLM 5'-RACE: RNA ligase-mediated 5' rapid amplification of cDNA ends; ROS: Reactive oxygen species; SODX: Superoxide dismutaseX; TF: Transcription factor; ZDRE: Zinc deficiency response element; ZIFL: Zinc-induced facilitator; ZIP: ZRT, IRT-related protein; Zn: Zinc

\section{Acknowledgements}

We thank Dr. Jin Xu (Xishuangbanna Tropical Botanical Garden, Chinese Academy of Sciences) for critical reading of this manuscript.

\section{Authors' contributions}

H.Z. and Y.Z. conceived the study and designed the experiments. H.Z., X.Z., and M.D. performed the experiments. H.Z. and Y.Z. analyzed the data and wrote the manuscript. All authors read and approved the final manuscript.

\section{Funding}

This work was supported by the Zhejiang Provincial Natural Science Foundation of China (No. LY20C150002) and the National Natural Science Foundation of China (No. 31471937 and No. 31800201). The funders have no role in the study design, data analysis and interpretation, and manuscript writing, but just provide the financial supports.

\section{Availability of data and materials}

The datasets used during the current study are available from the corresponding author on reasonable request.

\section{Ethics approval and consent to participate} Not applicable.

\section{Consent for publication}

Not applicable.

\section{Competing interests}

The authors declare that they have no competing interests.

\section{Author details}

${ }^{1}$ College of Life and Environmental Sciences, Hangzhou Normal University, Hangzhou 311121, China. ${ }^{2}$ College of Agriculture and Biotechnology, Hunan University of Humanities, Science and Technology, Loudi 417000, China. ${ }^{3}$ College of Resources and Environmental Sciences, Nanjing Agricultural University, Nanjing 210095, China.

Received: 23 September 2019 Accepted: 15 December 2019 Published online: 26 December 2019

\section{References}

1. Broadley MR, White PJ, Hammond JP, Zelko I, Lux A. Zinc in plants. New Phytol. 2007;173(4):677-702.

2. Li Y, Zhang Y, Shi D, Liu X, Qin J, Ge Q, Xu L, Pan X, Li W, Zhu Y, et al. Spatial-temporal analysis of zinc homeostasis reveals the response mechanisms to acute zinc deficiency in Sorghum bicolor. New Phytol. 2013; 200(4):1102-15.

3. Alloway B. Soil factors associated with zinc deficiency in crops and humans. Environ Geochem Health. 2009;31(5):537-48.

4. Cakmak I. Enrichment of cereal grains with zinc: agronomic or genetic biofortification? Plant Soil. 2008;302(1-2):1-17.
5. Brown KH, Rivera JA, Bhutta Z, Gibson RS, King JC, Lonnerdal B, Ruel MT, Sandtrom B, Wasantwisut E, Hotz C. International zinc nutrition consultative group (IZiNCG) technical document \#1. Assessment of the risk of zinc deficiency in populations and options for its control. Food Nutr Bull. 2004; 25(1 Suppl 2):S99-203.

6. Rose TJ, Impa SM, Rose MT, Pariasca-Tanaka J, Mori A, Heuer S, JohnsonBeebout SE, Wissuwa M. Enhancing phosphorus and zinc acquisition efficiency in rice: a critical review of root traits and their potential utility in rice breeding. Ann Bot. 2012;112:331-45.

7. Sinclair SA, Krämer U. The zinc homeostasis network of land plants. Biochimica et Biophysica Acta (BBA) - Mol Cell Res. 2012;1823(9):1553-67.

8. Ishimaru Y, Bashir K, Nishizawa NK. Zn uptake and translocation in rice plants. Rice. 2011;4(1):21-7.

9. White JG, Zasoski RJ. Mapping soil micronutrients. Field Crop Res. 1999; 60(1):11-26.

10. Lee J-S, Sajise AGC, Gregorio GB, Kretzschmar T, Ismail AM, Wissuwa M. Genetic dissection for zinc deficiency tolerance in rice using bi-parental mapping and association analysis. Theor Appl Genet. 2017;130(9):1903-14.

11. Cakmak I. Possible roles of zinc in protecting plant cells from damage by reactive oxygen species. New Phytol. 2000;146(2):185-205.

12. Impa SM, Johnson-Beebout SE. Mitigating zinc deficiency and achieving high grain $\mathrm{Zn}$ in rice through integration of soil chemistry and plant physiology research. Plant Soil. 2012;361(1):3-41.

13. Hacisalihoglu G, Hart JJ, Wang Y-H, Cakmak I, Kochian LV. Zinc efficiency is correlated with enhanced expression and activity of zinc-requiring enzymes in wheat. Plant Physiol. 2003;131(2):595.

14. Cavagnaro T. The role of arbuscular mycorrhizas in improving plant zinc nutrition under low soil zinc concentrations: a review. Plant Soil. 2008; 304(1-2):315-25.

15. Widodo B, Broadley MR, Rose T, Frei M, Pariasca-Tanaka J, Yoshihashi T, Thomson M, Hammond JP, Aprile A, Close TJ, et al. Response to zinc deficiency of two rice lines with contrasting tolerance is determined by root growth maintenance and organic acid exudation rates, and not by zinctransporter activity. New Phytol. 2010;186(2):400-14.

16. Mori A, Kirk GJ, Lee JS, Morete MJ, Nanda AK, Johnson-Beebout SE, Wissuwa M. Rice genotype differences in tolerance of zinc-deficient soils: evidence for the importance of root-induced changes in the Rhizosphere. Front Plant Sci. 2015;6:1160.

17. Ishimaru Y, Masuda H, Suzuki M, Bashir K, Takahashi M, Nakanishi H, Mori S, Nishizawa NK. Overexpression of the OsZIP4 zinc transporter confers disarrangement of zinc distribution in rice plants. J Exp Bot. 2007;58(11): 2909-15.

18. Olsen LI, Hansen TH, Larue C, Osterberg JT, Hoffmann RD, Liesche J, Kramer U, Surble S, Cadarsi S, Samson VA, et al. Mother-plant-mediated pumping of zinc into the developing seed. Nat Plants. 2016;2(5):16036.

19. Cai H, Huang S, Che J, Yamaji N, Ma JF. The tonoplast-localized transporter OsHMA3 plays an important role in maintaining $\mathrm{Zn}$ homeostasis in rice. J Exp Bot. 2019;70(10):2717-25

20. Sasaki A, Yamaji N, Mitani-Ueno N, Kashino M, Ma JF. A node-localized transporter OsZIP3 is responsible for the preferential distribution of $\mathrm{Zn}$ to developing tissues in rice. Plant J. 2015;84(2):374-84.

21. Sinclair SA, Senger T, Talke IN, Cobbett CS, Haydon MJ, Kramer U. Systemic Upregulation of MTP2- and HMA2-mediated Zn partitioning to the shoot supplements local Zn deficiency responses. Plant Cell. 2018;30(10):2463-79.

22. Nanda AK, Pujol V, Wissuwa M. Patterns of stress response and tolerance based on transcriptome profiling of rice crown tissue under zinc deficiency. J Exp Bot. 2017;68(7):1715-29.

23. Zeng $H$, Zhang $X$, Ding $M$, Zhang $X$, Zhu Y. Transcriptome profiles of soybean leaves and roots in response to zinc deficiency. Physiol Plant. 2019;167:330-51.

24. Bandyopadhyay T, Mehra P, Hairat S, Giri J. Morpho-physiological and transcriptome profiling reveal novel zinc deficiency-responsive genes in rice. Funct Integr Genomics. 2017;17(5):565-81.

25. Bartel DP. MicroRNAs: genomics, biogenesis, mechanism, and function. Cell. 2004;116(2):281-97.

26. Song X, Li Y, Cao X, Qi Y. MicroRNAs and their regulatory roles in plantenvironment interactions. Annu Rev Plant Biol. 2019;70:489-525.

27. Tang J, Chu C. MicroRNAs in crop improvement: fine-tuners for complex traits. Nat Plants. 2017;3(7):17077.

28. Li S, Castillo-Gonzalez C, Yu B, Zhang X. The functions of plant small RNAs in development and in stress responses. Plant J. 2017;90(4):654-70. 
29. Khraiwesh B, Zhu JK, Zhu J. Role of miRNAs and siRNAs in biotic and abiotic stress responses of plants. Biochim Biophys Acta. 2012;1819(2):137-48.

30. Gao S, Yang L, Zeng HQ, Zhou ZS, Yang ZM, Li H, Sun D, Xie F, Zhang B. A cotton miRNA is involved in regulation of plant response to salt stress. Sci Rep. 2016;6:19736.

31. Meng $Y$, Shao $C$, Wang $H$, Chen $M$. The regulatory activities of plant microRNAs: a more dynamic perspective. Plant Physiol. 2011;157(4):1583-95.

32. Chen Z, Hu L, Han N, Hu J, Yang Y, Xiang T, Zhang X, Wang L Overexpression of a miR393-resistant form of transport inhibitor response protein 1 (mTIR1) enhances salt tolerance by increased osmoregulation and $\mathrm{Na}+$ exclusion in Arabidopsis thaliana. Plant Cell Physiol. 2015;56(1):73-83.

33. Shao $Y$, Zhou HZ, Wu Y, Zhang H, Lin J, Jiang $X$, He Q, Zhu J, Li Y, Yu H, et al. OsSPL3, an SBP-domain protein, regulates crown root development in Rice. Plant Cell. 2019;31(6):1257-75.

34. Hong $Y$, Jackson S. Floral induction and flower formation--the role and potential applications of miRNAs. Plant Biotechnol J. 2015;13(3):282-92.

35. Fang Y, Xie K, Xiong L. Conserved miR164-targeted NAC genes negatively regulate drought resistance in rice. J Exp Bot. 2014;65(8):2119-35.

36. Kim JH, Woo HR, Kim J, Lim PO, Lee IC, Choi SH, Hwang D, Nam HG. Trifurcate feed-forward regulation of age-dependent cell death involving miR164 in Arabidopsis. Science. 2009:323(5917):1053-7.

37. Jiang D, Chen W, Dong J, Li J, Yang F, Wu Z, Zhou H, Wang W, Zhuang C. Overexpression of miR164b-resistant OsNAC2 improves plant architecture and grain yield in rice. J Exp Bot. 2018;69(7):1533-43.

38. Zeng $H$, Wang $G, H u X$, Wang $H$, Du L, Zhu Y. Role of microRNAs in plant responses to nutrient stress. Plant Soil. 2014;374:1005-21.

39. Pilon M. The copper microRNAs. New Phytol. 2017;213(3):1030-5.

40. Liu TY, Lin WY, Huang TK, Chiou TJ. MicroRNA-mediated surveillance of phosphate transporters on the move. Trends Plant Sci. 2014;19(10):647-55.

41. Wang L, Zeng HQ, Song J, Feng SJ. Yang ZM: miRNA778 and SUVH6 are involved in phosphate homeostasis in Arabidopsis. Plant Sci. 2015;238:273-85.

42. Hu B, Zhu C, Li F, Tang J, Wang Y, Lin A, Liu L, Che R, Chu C. LEAF TIP NECROSIS1 plays a pivotal role in the regulation of multiple phosphate starvation responses in rice. Plant Physiol. 2011;156(3):1101-15.

43. Lin WY, Huang TK, Chiou TJ. Nitrogen limitation adaptation, a target of microRNA827, mediates degradation of plasma membrane-localized phosphate transporters to maintain phosphate homeostasis in Arabidopsis. Plant Cell. 2013;25(10):4061-74.

44. Zhang H, Zhao X, Li J, Cai H, Deng XW, Li L. MicroRNA408 is critical for the HY5-SPL7 gene network that mediates the coordinated response to light and copper. Plant Cell. 2014;26(12):4933-53.

45. Jeong DH, Park S, Zhai J, Gurazada SG, De Paoli E, Meyers BC, Green PJ. Massive analysis of rice small RNAs: mechanistic implications of regulated microRNAs and variants for differential target RNA cleavage. Plant Cell. 2011; 23(12):4185-207.

46. Dai $X$, Zhao PX. psRNATarget: a plant small RNA target analysis server. Nucleic Acids Res. 2011;39(Web Server issue):W155-9.

47. Li YF, Zheng Y, Addo-Quaye C, Zhang L, Saini A, Jagadeeswaran G, Axtell MJ, Zhang W, Sunkar R. Transcriptome-wide identification of microRNA targets in rice. Plant J. 2010;62(5):742-59.

48. Zhou M, Gu L, Li P, Song X, Wei L, Chen Z, Cao X. Degradome sequencing reveals endogenous small RNA targets in rice (Oryza sativa L. ssp. indica). Front Biol. 2010;5(1):67-90.

49. Pan J, Huang D, Guo Z, Kuang Z, Zhang H, Xie X, Ma Z, Gao S, Lerdau MT, Chu C, et al. Overexpression of microRNA408 enhances photosynthesis, growth, and seed yield in diverse plants. J Integr Plant Biol. 2018;60(4):323-40.

50. Lu Y, Feng Z, Bian L, Xie H. Liang J: miR398 regulation in rice of the responses to abiotic and biotic stresses depends on CSD1 and CSD2 expression. Funct Plant Biol. 2011;38(1):44.

51. Guan Q, Lu X, Zeng H, Zhang Y, Zhu J. Heat stress induction of miR398 triggers a regulatory loop that is critical for thermotolerance in Arabidopsis. Plant J. 2013;74(5):840-51.

52. Li Y, Cao XL, Zhu Y, Yang XM, Zhang KN, Xiao ZY, Wang H, Zhao JH, Zhang $\mathrm{LL}$, Li GB, et al. Osa-miR398b boosts $\mathrm{H} 2 \mathrm{O} 2$ production and rice blast disease-resistance via multiple superoxide dismutases. New Phytol. 2019; 222(3):1507-22.

53. Ma C, Burd S. Lers a: miR408 is involved in abiotic stress responses in Arabidopsis. Plant J. 2015;84(1):169-87.

54. Zhang JP, Yu Y, Feng YZ, Zhou YF, Zhang F, Yang YW, Lei MQ, Zhang YC, Chen YQ. MiR408 regulates grain yield and photosynthesis via a Phytocyanin protein. Plant Physiol. 2017;175(3):1175-85.
55. Yuan S, Li Z, Li D, Yuan N, Hu Q, Luo H. Constitutive expression of Rice MicroRNA528 alters plant development and enhances tolerance to salinity stress and nitrogen starvation in creeping Bentgrass. Plant Physiol. 2015; 169(1):576-93.

56. Wu J, Yang R, Yang Z, Yao S, Zhao S, Wang Y, Li P, Song X, Jin L, Zhou T, et al. ROS accumulation and antiviral defence control by microRNA528 in rice. Nat Plants. 2017;3:16203

57. Zhang YC, Yu Y, Wang CY, Li ZY, Liu Q, Xu J, Liao JY, Wang XJ, Qu LH, Chen $F$, et al. Overexpression of microRNA OsmiR397 improves rice yield by increasing grain size and promoting panicle branching. Nat Biotechnol. 2013;31(9):848-52

58. Xue C, Yao JL, Qin MF, Zhang MY, Allan AC, Wang DF, Wu J. PbrmiR397a regulates lignification during stone cell development in pear fruit. Plant Biotechnol J. 2019;17(1):103-17.

59. Pant BD, Musialak-Lange M, Nuc P, May P, Buhtz A, Kehr J, Walther D, Scheible WR. Identification of nutrient-responsive Arabidopsis and rapeseed microRNAs by comprehensive real-time polymerase chain reaction profiling and small RNA sequencing. Plant Physiol. 2009;150(3):1541-55.

60. Lee S, Jeong HJ, Kim SA, Lee J, Guerinot ML, An G. OsZIP5 is a plasma membrane zinc transporter in rice. Plant Mol Biol. 2010;73(4):507-17.

61. Liang G, Yang F, Yu D. MicroRNA395 mediates regulation of sulfate accumulation and allocation in Arabidopsis thaliana. Plant J. 2010;62(6): 1046-57.

62. Lu YB, Qi YP, Yang LT, Guo P, Li Y, Chen LS. Boron-deficiency-responsive microRNAs and their targets in Citrus sinensis leaves. BMC Plant Biol. 2015; $15: 271$.

63. Wu L, Zhou H, Zhang Q, Zhang J, Ni F, Liu C, Qi Y. DNA methylation mediated by a microRNA pathway. Mol Cell. 2010;38(3):465-75.

64. Cuperus JT, Fahlgren N, Carrington JC. Evolution and functional diversification of MIRNA genes. Plant Cell. 2011;23(2):431-42.

65. Secco D, Whelan J, Rouached H, Lister R. Nutrient stress-induced chromatin changes in plants. Curr Opin Plant Biol. 2017;39:1-7.

66. Hafeez B, Khanif Y, Saleem M. Role of zinc in plant nutrition-a review. Am J Exp Agri. 2013;3(2):374-91.

67. Kausar MA, Chaudhry FM, Rashid A, Latif A, Alam SM. Micronutrient availability to cereals from calcareous soils. Plant Soil. 1976;45(2):397-410.

68. Dong C, He F, Berkowitz O, Liu J, Cao P, Tang M, Shi H, Wang W, Li Q, Shen $Z$, et al. Alternative splicing plays a critical role in maintaining mineral nutrient homeostasis in Rice (Oryza sativa). Plant Cell. 2018;30(10):2267-85.

69. Yamasaki H, Abdel-Ghany SE, Cohu CM, Kobayashi Y, Shikanai T, Pilon M. Regulation of copper homeostasis by micro-RNA in Arabidopsis. J Biol Chem. 2007;282(22):16369-78.

70. Abdel-Ghany SE, Pilon M. MicroRNA-mediated systemic down-regulation of copper protein expression in response to low copper availability in Arabidopsis. J Biol Chem. 2008;283(23):15932-45.

71. Frei M, Wang Y, Ismail AM, Wissuwa M. Biochemical factors conferring shoot tolerance to oxidative stress in rice grown in low zinc soil. Funct Plant Biol. 2010;37(1):74-84.

72. Lee JS, Wissuwa M, Zamora OB, Ismail AM. Biochemical indicators of root damage in rice (Oryza sativa) genotypes under zinc deficiency stress. J Plant Res. 2017;130(6):1071-7.

73. Sunkar R, Kapoor A, Zhu JK. Posttranscriptional induction of two cu/Zn superoxide dismutase genes in Arabidopsis is mediated by downregulation of miR398 and important for oxidative stress tolerance. Plant Cell. 2006; 18(8):2051-65.

74. Zeng HQ, Liu G, Kinoshita T, Zhang RP, Zhu YY, Shen QR, Xu GH. Stimulation of phosphorus uptake by ammonium nutrition involves plasma membrane H+ ATPase in rice roots. Plant Soil. 2012;357(1-2):205-14.

75. Yoshida S, Forno DA, Cock JH. Laboratory manual for physiological studies of rice. Manila: International Rice Research Institute; 1971.

76. Liu XS, Feng SJ, Zhang BQ, Wang MQ, Cao HW, Rono JK, Chen X, Yang ZM. OsZIP1 functions as a metal efflux transporter limiting excess zinc, copper and cadmium accumulation in rice. BMC Plant Biol. 2019;19(1):283.

77. Trapnell C, Pachter L, Salzberg SL. TopHat: discovering splice junctions with RNA-Seq. Bioinformatics. 2009;25(9):1105-11.

78. Ashburner M, Ball CA, Blake JA, Botstein D, Butler H, Cherry JM, Davis AP, Dolinski K, Dwight SS, Eppig JT, et al. Gene ontology: tool for the unification of biology. Gene Ontol Cons Nat Genet. 2000;25(1):25-9.

79. Du Z, Zhou X, Ling Y, Zhang Z, Su Z. agriGO: a GO analysis toolkit for the agricultural community. Nucleic Acids Res. 2010;38(Web Server issue):W64-70. 
80. Axtell MJ, Meyers BC. Revisiting criteria for plant MicroRNA annotation in the era of big data. Plant Cell. 2018;30(2):272-84.

81. Zeng H, Zhang Y, Zhang X, Pi E, Zhu Y. Analysis of EF-hand proteins in soybean genome suggests their potential roles in environmental and nutritional stress signaling. Front Plant Sci. 2017;8(877):877.

82. Zeng HQ, Zhu YY, Huang SQ, Yang ZM. Analysis of phosphorus-deficient responsive miRNAs and cis-elements from soybean (Glycine max L.). J Plant Physiol. 2010;167(15):1289-97.

83. Pfaffl MW. A new mathematical model for relative quantification in real-time RT-PCR. Nucleic Acids Res. 2001;29(9):e45.

\section{Publisher's Note}

Springer Nature remains neutral with regard to jurisdictional claims in published maps and institutional affiliations.

Ready to submit your research? Choose BMC and benefit from:

- fast, convenient online submission

- thorough peer review by experienced researchers in your field

- rapid publication on acceptance

- support for research data, including large and complex data types

- gold Open Access which fosters wider collaboration and increased citations

- maximum visibility for your research: over $100 \mathrm{M}$ website views per year

At BMC, research is always in progress.

Learn more biomedcentral.com/submissions 